\title{
On the importance of small ice crystals in tropical anvil cirrus
}

\author{
E. J. Jensen ${ }^{1}$, P. Lawson ${ }^{2}$, B. Baker ${ }^{2}$, B. Pilson ${ }^{2}$, Q. Mo $^{2}$, A. J. Heymsfield ${ }^{3}$, A. Bansemer ${ }^{3}$, T. P. Bui ${ }^{1}$, M. McGill ${ }^{4}$, \\ D. Hlavka $^{4}$, G. Heymsfield ${ }^{4}$, S. Platnick ${ }^{4}$, G. T. Arnold ${ }^{4}$, and S. Tanelli ${ }^{5}$ \\ ${ }^{1}$ NASA Ames Research Center, Moffett Field, CA, USA \\ ${ }^{2}$ SPEC Inc., Boulder, CO, USA \\ ${ }^{3}$ National Center for Atmospheric Research, Boulder, CO, USA \\ ${ }^{4}$ NASA Goddard Space Flight Center, Greenbelt, MD, USA \\ ${ }^{5}$ Jet Propulsion Laboratory, California Institute of Technology, Pasadena, CA, USA
}

Received: 29 January 2009 - Published in Atmos. Chem. Phys. Discuss.: 2 March 2009

Revised: 21 July 2009 - Accepted: 22 July 2009 - Published: 6 August 2009

\begin{abstract}
In situ measurements of ice crystal concentrations and sizes made with aircraft instrumentation over the past two decades have often indicated the presence of numerous relatively small $(<50 \mu \mathrm{m}$ diameter) crystals in cirrus clouds. Further, these measurements frequently indicate that small crystals account for a large fraction of the extinction in cirrus clouds. The fact that the instruments used to make these measurements, such as the Forward Scattering Spectrometer Probe (FSSP) and the Cloud Aerosol Spectrometer (CAS), ingest ice crystals into the sample volume through inlets has led to suspicion that the indications of numerous small-crystals could be artifacts of large-crystal shattering on the instrument inlets. We present new aircraft measurements in anvil cirrus sampled during the Tropical Composition, Cloud, and Climate Coupling (TC4) campaign with the 2-Dimensional Stereo (2D-S) probe, which detects particles as small as $10 \mu \mathrm{m}$. The 2D-S has detector "arms" instead of an inlet tube. Since the 2D-S probe surfaces are much further from the sample volume than is the case for the instruments with inlets, it is expected that 2D-S will be less susceptible to shattering artifacts. In addition, particle interarrival times are used to identify and remove shattering artifacts that occur even with the 2D-S probe. The number of shattering artifacts identified by the 2D-S interarrival time analysis ranges from a negligible contribution to an order of magnitude or more enhancement in apparent ice concentration over the natural ice concentration, depending on the abundance of large crystals and the natural small-crystal concentration. The 2D-S measurements in tropical anvil cirrus suggest that natural small-crystal concentrations are typically one to two orders of magnitude lower than those inferred from CAS. The strong correlation between the CAS/2D-S ra-
\end{abstract}

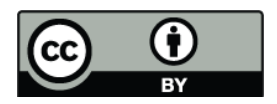

Correspondence to: E. J. Jensen (eric.j.jensen@nasa.gov) tio of small-crystal concentrations and large-crystal concentration suggests that the discrepancy is likely caused by shattering of large crystals on the CAS inlet. We argue that past measurements with CAS in cirrus with large crystals present may contain errors due to crystal shattering, and past conclusions derived from these measurements may need to be revisited. Further, we present correlations between CAS spurious concentration and 2D-S large-crystal mass from spatially uniform anvil cirrus sampling periods as an approximate guide for estimating quantitative impact of large-crystal shattering on CAS concentrations in previous datasets. We use radiative transfer calculations to demonstrate that in the maritime anvil cirrus sampled during TC4, small crystals indicated by $2 \mathrm{D}-\mathrm{S}$ contribute relatively little cloud extinction, radiative forcing, or radiative heating in the anvils, regardless of anvil age or vertical location in the clouds. While 2D-S ice concentrations in fresh anvil cirrus may often exceed $1 \mathrm{~cm}^{-3}$, and are observed to exceed $10 \mathrm{~cm}^{-3}$ in turrets, they are typically $\simeq 0.1 \mathrm{~cm}^{-3}$ and rarely exceed $1 \mathrm{~cm}^{-3}(<1.4 \%$ of the time) in aged anvil cirrus. We hypothesize that isolated occurrences of higher ice concentrations in aged anvil cirrus may be caused by ice nucleation driven by either small-scale convection or gravity waves. It appears that the numerous small crystals detrained from convective updrafts do not persist in the anvil cirrus sampled during TC-4.

\section{Introduction}

Accurate information about cirrus ice crystal size distributions is important for a number of reasons. The balance between cirrus longwave and solar cloud radiative forcing depends, among other factors, on ice crystal size (Stackhouse and Stephens, 1991; Jensen et al., 1994). Cloud remotesensing measurements typically measure only part of the size

Published by Copernicus Publications on behalf of the European Geosciences Union. 
distribution. In order to retrieve parameters such as ice water content, apriori information about the shape of ice crystal size distributions is required. Sanderson et al. (2008) recently used an ensemble of thousands of general circulation model (GCM) simulations with perturbed cloud parameterizations to evaluate the relative impact of different cloud parameters on climate sensitivity in the model. One of the two leading factors was ice crystal fallspeed, which is a function of the ice crystal size assumed in the cirrus parameterizations. Mitchell et al. (2008) showed that cirrus ice mass, cirrus coverage, and cloud radiative forcing simulated in a climate model are very sensitive to assumptions about the concentration of small (diameter $<60 \mu \mathrm{m}$ ) crystals in the cirrus parameterization. Lastly, if we are to evaluate potential impacts of anthropogenic aerosols on cirrus microphysical and radiative properties, we must first have reliable information about ice crystal sizes and concentrations.

Airborne in situ instruments have been used on aircraft to measure the sizes and concentrations of ice crystals in cirrus clouds for more than three decades. If we focus on the small end of the cirrus ice size spectrum $(<50 \mu \mathrm{m}$ diameter), the vast majority of the measurements were made with FSSP-type (Forward-Scattering Spectrometer Probe) instruments that measure the scattering of light from the crystals, and retrieve the crystal size using Mie scattering theory. Instruments based on this technique include the FSSP100, FSSP-300, SPP-100, MASP (Multi-Angle Spectrometer Probe), and the CAS (Cloud Aerosol Spectrometer) component of CAPS (Cloud, Aerosol, Precipitation Spectrometer) (Baumgardner et al., 2001). More recently, Counterflow Virtual Impactors (CVIs) have been used to infer ice crystal concentrations (Ström et al., 1997) by counting the residual particles after ice sublimation and assuming one residual particle per ice crystal. These in situ measurements have been used to characterize the microphysical and radiative properties of both midlatitude cirrus (e.g. Ivanova et al., 2001; Lawson et al., 2006a) and tropical cirrus (e.g. Platt et al., 1989; Knollenberg et al., 1993; Garrett et al., 2005). The common aspect of the above instruments is that they all ingest ice crystals through an inlet and are flown on jet aircraft (for cirrus measurements) at high speeds, raising the possibility of small-particle artifacts due to large-crystal shattering.

The measurements of abundant small crystals have been questioned for several reasons. As an example, the CAS measurements in anvil cirrus from the Cirrus Regional Study of Tropical Anvils and Cirrus Layers - Florida Area Cirrus Experiment (CRYSTAL-FACE) are suspicious for a number of reasons: first, abundant small crystals are indicated throughout the clouds (in fresh anvils, in aged anvils, and throughout the vertical extent of the clouds) (Garrett et al., 2005). Size sorting as anvils age should produce regions in the lower parts of the clouds where large crystals are present with few small crystals. Second, effective radii derived from the CAPS measurements are typically in the 5-20 $\mu \mathrm{m}$ range; these values are substantially smaller than those derived from remote-sensing measurements (typically 30-40 $\mu \mathrm{m}$ ) (Hong et al., 2007). Lastly, there is a strong correlation between small-crystal concentration derived from CAS and largecrystal mass derived from imaging probes such as CIP or 2D-C (Heymsfield, 2007). Such a correlation to be expected if shattering of large crystals dominates the measured concentration of small crystals.

We refer here to crystals with lengths less than $50 \mu \mathrm{m}$ as "small crystals". Past studies debated the role of small crystals for tropical anvil cirrus albedo, defining "small" as less than 20-25 $\mu \mathrm{m}$ (Knollenberg et al., 1993; Zender and Kiehl, 1994; Heymsfield and McFarquhar, 1996; McFarquhar and Heymsfield, 1997). Some of these studies indicated even these very small crystals were important, while others concluded the small crystals had little impact on cirrus albedo. We use a larger upper limit $(50 \mu \mathrm{m})$ here because the entire size range from about $10 \mu \mathrm{m}$ to the upper size limit of the CAS spectrometer seems to be affected by crystal shattering (McFarquhar et al., 2007).

Past studies have provided mixed evidence about the plausibility of large concentrations of small crystals $\left(>1 \mathrm{~cm}^{-3}\right.$ crystals smaller than $\simeq 50 \mu \mathrm{m}$ ) in ice clouds. Gardiner and Hallett (1985) compared FSSP measurements with replicator measurements and concluded that the FSSP-measured ice concentrations could be erroneously enhanced by orders of magnitude in the presence of large, irregular ice crystals. However, Ivanova et al. (2001) argued that the counting efficiency of the replicator decreases with decreasing crystal size such that one would expect undercounting of small crystals. Gayet et al. (1996) compared FSSP and 2D-C measurements and concluded that FSSP concentrations are exaggerated in cirrus with large crystals. However, Gayet et al. (2002) and Lawson et al. (2006a) measured FSSP concentrations of small ice greater than $1 \mathrm{~cm}^{-3}$ in midlatitude cirrus in the absence of crystals larger than $100 \mu \mathrm{m}$. Field et al. (2003) evaluated the interarrival times for crystals in the FSSP instrument sampling midlatitude cirrus and concluded that the crystal concentrations can be exaggerated by factors of 2-3 and occasionally by as much as a factor of 5 . We note that much larger crystals were present in the anvil cirrus discussed here than in the midlatitude cirrus analyzed by Field et al. (2003). As shown by Korolev and Isaac (2005), the number of fragments produced by shattering increases rapidly with the size of the large crystals. Hence, the exaggeration of small-crystal concentration due to shattering is likely to be much larger for the tropical anvil cirrus discussed here than the Field et al. (2003) analysis suggested for midlatitude cirrus. Heymsfield (2007) recently compared extinction and ice water content measured with FSSP and CAS with extinction and ice water content derived from 2D$\mathrm{C}$ and counterflow virtual impactor measurements. The conclusion drawn from this analysis was that the former probes are measuring a combination of natural small crystals and shattered large ice crystals. Recently, Davis et al. (2009) compared optical depth derived from a number of instrument 
probes (including CAPS) used during the WB57 Mid Latitude Cirrus Experiment (MIDCIX) with remote-sensing retrievals from the Moderate Resolution Imaging Spectrometer (MODIS). In general the in situ probe optical depths were higher than the MODIS optical depths, and the CAPS optical depths were the highest of the in situ probes. Davis et al. (2009) concluded that these results were consistent with past studies suggesting shattering artifacts in the CAS measurements.

Despite evidence indicating that shattering at inlets may produce small-crystal artifacts, some recent publications have still argued for the common presence of high concentrations of small crystals in cirrus, and the measurements have been used at face value to make inferences about ice nucleation processes and cloud radiative properties. For example, Garrett et al. (2005) analyzed CAS measurements in subtropical anvil cirrus and concluded that small crystals dominate the crystal size distribution and anvil radiative properties. Other studies have used the in situ measurements to suggest anomalous nucleation of crystals at cloud boundaries or evaporation zones (e.g. Cotton and Field, 2002).

Kärcher and Ström (2003) reported CVI measurements indicating cirrus clouds typically contained high concentrations $\left(1-10 \mathrm{~cm}^{-3}\right.$ ) of very small (diameter $<20 \mu \mathrm{m}$ ) ice crystals. They showed that these large ice concentrations could be explained by ice nucleation driven by rapid gravity-wave driven cooling. However, the simulations only represented ice concentrations at the time and location where nucleation occurred. Cloud aging processes (entrainment, sedimentation, and aggregation) decrease ice concentration with time. One might expect that the CVI measurements included aged cirrus or precipitation zones where the existence of numerous small crystals would not be expected. CVI measurements of ice concentration can be subject to shattering artifacts if multiple shattering fragments contain sufficient soluble or insoluble material to produce detectable residual particles. Hoyle et al. (2005) conducted a similar study comparing parcel-model simulations with ice concentration measurements from a Multiangle Aerosol Spectrometer Probe (MASP, similar to CAS) and a CVI in cirrus during the Subsonic Aircraft: Contrail and Cloud Effects Special Study (SUCCESS). They also concluded that high ice concentrations $\left(1-10 \mathrm{~cm}^{-3}\right)$ are commonplace in midlatitude cirrus.

Fridlind et al. (2004) used CAPS measurements as evidence for the importance of middle and upper tropospheric aerosols in the production of ice crystals that dominate the ice concentration in subtropical anvils. This issue is important for evaluating the relationship between aerosol properties and cumulonimbus anvil microphysical properties and radiative effects. If boundary-layer aerosols dominate production of ice crystals in the clouds, then local pollution sources could affect anvil properties. If aerosols entrained into updrafts in the free troposphere dominate, then longrange transport and remote sources must be considered. As discussed further below, the conclusions of this study may need to be revisited given the indications of shattering artifacts in CAPS measurements of small crystals in anvil cirrus.

Recently, the Cloud Droplet Probe (CDP) was used to sample tropical anvil cirrus during the Tropical Warm Pool - Ice Crystal Experiment (TWP-ICE). Since it does not ingest ice crystals into the sample volume through an inlet, but instead has probe arms, the CDP was expected to produce relatively fewer shattering artifacts than the probes with inlet tubes. McFarquhar et al. (2007) compared CDP and CAS anvil size distributions and showed that the CAS concentrations of small crystals appear to be overestimated by approximately two orders of magnitude when large crystals are present. The correlation between the ratio of CAS and CDP small-crystal concentrations and the concentration of large $(>100 \mu \mathrm{m})$ crystals is consistent with the hypothesis that the enhanced CAS concentrations result from shattering of large crystals impacting the instrument inlet.

The need to avoid the shattering problem and provide reliable information about small-crystal concentrations has motivated development of balloon-borne replicators. These replicators also provide sufficient resolution to determine ice crystal habits. Replicators were successfully launched during several field experiments (Miloshevich and Heymsfield, 1997). In addition, the Video Ice Particle Sampler (VIPS) is designed to measure ice particles as small as $\simeq 10-20 \mu \mathrm{m}$ by impacting them on a transparent moving belt, followed by imaging the crystals with a video microscope (Heymsfield and Miloshevich, 1995).

Here, we present CAPS measurements of ice crystal size distributions in tropical anvil cirrus from the the Tropical Composition, Cloud, and Climate Coupling (TC4) experiment. As in other datasets from instruments with inlets, the CAPS measurements indicate the presence of high concentrations of small crystals throughout the vertical and horizontal extents and ages of the clouds sampled. We also compare the TC4 CAPS measurements with measurements from the 2 Dimensional Stereo (2D-S) probe, which has the demonstrated ability to image ice crystals as small as $10 \mu \mathrm{m}$ (Lawson et al., 2006b). We find that the anvil cirrus small-particle concentrations indicated by the CAS component of CAPS generally exceed those indicated by $2 \mathrm{D}-\mathrm{S}$ by $1-2$ orders of magnitude in the 10-50 $\mu \mathrm{m}$ size range where the instruments overlap. The CAS/2D-S concentration ratio is strongly correlated with large-crystal mass, suggesting that the discrepancy is caused by shattering of large crystals on the CAS inlet.

Using the 2D-S dataset, we show that small crystals have little effect on extinction, radiative forcing, and radiative heating for the tropical anvil cirrus sampled during TC4. We show that high concentrations (as large as $30 \mathrm{~cm}^{-3}$ in turrets and $>1 \mathrm{~cm}^{-3}$ in fresh convective anvil outflow) of small crystals do occur, but even in these locations, larger crystals dominate the cloud extinction. Also, it appears that the numerous small crystals detrained from deep convection do not persist as the anvil cirrus ages. Lastly, we show that concentrations can exceed $1 \mathrm{~cm}^{-3}$ in isolated locations in aged 
anvil cirrus well away from active convection; there is some evidence suggesting that the latter occurrences are associated with either small-scale convection or gravity waves.

\section{Instrument descriptions}

The TC4 mission, based in San Jose, Costa Rica, included extensive sampling of tropical anvil cirrus, using CAPS and 2D-S measurements both on the WB-57 and the NASA DC8 aircraft. CAPS consists of two instruments: the Cloud Aerosol Spectrometer (CAS) retrieves particle sizes by measuring light scattered off the particles and has an effective size range of $0.5-50 \mu \mathrm{m}$; the Cloud Imaging Probe (CIP) is similar to 2D-C instruments used for decades and captures images of ice crystals with sizes ranging from about 25 to $1550 \mu \mathrm{m}$. (The CIP pixel size is $25 \mu \mathrm{m}$ ). CAS measures both forward and backward scattering. Only the forward scattering signal is used in the data presented here, and in this mode, CAS is very similar to FSSP instruments commonly used for measurement of cloud and aerosol size distributions (Baumgardner et al., 2001).

In most previous field campaigns (including CRYSTALFACE and TWP-ICE), the CAS instrument has been flown with a shroud in front of the inlet. The purpose of the shroud is to straighten the airflow and remove dependence on aircraft angle of attack. However, the shroud provides an additional surface for potential shattering of large crystals, and calculations show that small-crystal fragments coming off the shroud could get swept into the CAS sample volume (McFarquhar et al., 2007). In fact, McFarquhar et al. (2007) argued that the shroud was predominantly responsible for the shattering artifacts in the TWP-ICE CAS data. In the hope of at least partially mitigating the shattering problem, during TC4 the CAS probe on the DC- 8 was flown without the shroud.

The 2D-S probe is actually two independent, identical optical array instruments housed in one canister. Hydrometeors are imaged in the air flowing between the four detector arms (see Fig. 1). The 2D-S imaging instrument operates on principles similar to the CIP probe. However, it has significantly smaller pixel size $(10 \mu \mathrm{m})$ and faster electronics, resulting in size distributions extending down to $10 \mu \mathrm{m}$ (Lawson et al., 2006b, 2008). It has been demonstrated that with the faster electronics the 2D-S can detect and count small particles at airspeeds up to $\simeq 230 \mathrm{~m} \mathrm{~s}^{-1}$. Likewise, the smaller pixel size allows detection of crystals that might have been missed by the CIP and 2D-C probes with larger pixel size. The sizing of crystal images that are out of focus in both the CIP and 2D-S datasets are corrected based on diffraction theory (Korolev, 2007).

The 2D-S probe shares the problem of rapidly decreasing sample volume with decreasing particle size that CIP suffers from, and this decreasing sample volume is accounted for in the same way for each of the probes. The depth of field

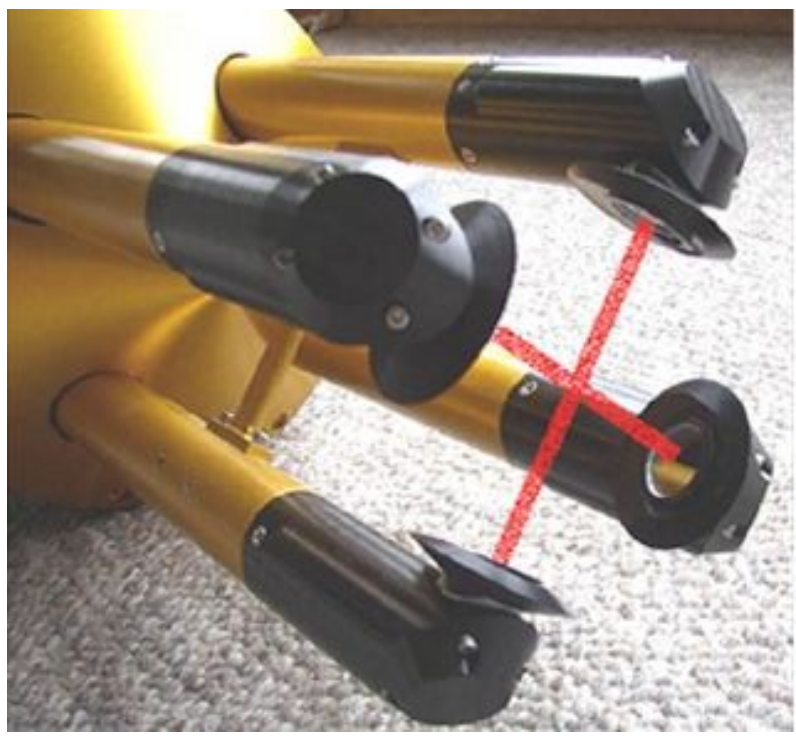

Fig. 1. 2D-S probe. The saucers on the detector arms are designed to minimize shattering fragments from entering the sample volume, which is near the middle of the path between the detector arms for small crystals. However, shattering fragments do still reach the sample volume and are apparent as clusters of small particles with very small inter-arrival times. These artifacts are removed using a detailed statistical analysis, as described by Baker et al. (2009) for the case of splashing raindrops. See text for details.

is assumed to be proportional to the square of the particle size. Experiments with glass beads were used to determine the coefficient in this relationship. A thorough investigation of the errors associated with depth of field effects on sample volume and corrections for out of focus particles has not been done. Therefore it is difficult to quantify the uncertainties in 2D-S measurements of small-crystal concentrations.

Although shattering artifacts do still occur in instruments such as CIP and 2D-S as a result of large crystals impacting the detector arms (Field et al., 2006), the shattering problem is expected to be less severe than for the CAS probe with its inlet. One reason for this expectation is that the detector arms protruding into the airstream are further from the sample volume than is the case for the CAS inlet. In addition, the 2D-S probe has sharp disks on the interior of the detector arms that are intended to deflect shattering artifacts away from the sample volume. While fewer shattering effects are expected with the construction of the 2D-S compared to the CAS or FSSP, numerous shattering fragments do still reach the sample volume and are apparent as groups of closely spaced particles. These spurious effects are removed (assuming ice particles are randomly distributed in clouds) using algorithms described by Baker et al. (2009) for the case of splashing raindrops, with the exception that tests for image roundness are excluded when processing ice data. The main strategy uses the close spacing of spurious particles 
to eliminate them, but some image processing techniques are also used. If the filtering algorithms are not employed the shattering effects on the 2D-S can be great at the smaller sizes when the natural concentration of small particles is low (Baker et al., 2009). The DC-8 CIP data were processed with a similar algorithm for removing shattering artifacts based on particle interarrival times.

It should be noted that if a large crystal shatters on the probe housing and only one of the fragments passes through the sample volume, then the interarrival time analysis will not identify the sampled fragment as an artifact. Although we believe such events are not common, they could result in an artificial enhancement of the 2D-S small-crystal measurements. Another possible source of artifacts is small crystals that bounce off the probe arms and are deflected into the sample volume. If either of these processes are significant, then the natural small crystal concentration will actually be less than the 2D-S results presented below. Our primary conclusion - that small crystal contribute relatively little to the TC4 anvil cirrus radiative properties - would thus not be affected by these artifacts. Also, if these artifacts are significant in the 2D-S measurements, it would imply that the CAS measurements of small-crystal concentration are exaggerated even more than we suggest below.

On the WB-57, the 2D-S probe was mounted under the wing about $2 \mathrm{~m}$ back from the wing leading edge, with the detector axis about $16 \mathrm{~cm}$ below the skin of the wing. There was concern that shattering artifacts resulting from large crystals impacting the wing leading edge might contaminate the instrument in this mounting location. This issue will be discussed further in Sect. 2.4. On the DC-8, the 2D-S and CAPS probes were mounted on wing pylons a couple of feet below the wing with the detectors slightly forward of the wing leading edge, and shattering from airframe surfaces should not have been a problem. The results presented here focus primarily on the DC- 8 measurements.

\subsection{TC4 anvil cirrus measurements}

During the July-August 2007 TC4 mission, tropical anvil cirrus with a range of ages and generated by a variety of types of deep convection were sampled, including fresh and aged outflow from Inter-Tropical Convergence Zone (ITCZ) systems, aged anvil cirrus generated by strong systems in the Panama Bight, and fresh outflow from systems along the coast of Costa Rica. In addition, on two DC- 8 flights, the aircraft flew through the tops of active turrets in unusually intense ITCZ systems. It should be noted that most of the anvil cirrus sampling was conducted well away from active convection for safety reasons.

First, we address the issue of shattering artifacts by comparing the CAPS measurements with the 2D-S measurements in the overlapping size range. As discussed above, 2D-S is expected to be less susceptible to shattering, and shattering artifacts are removed with the post-processing interarrival time analysis. As also discussed above, the shroud in front of the CAS probe on the DC-8 was removed for the TC4 campaign, potentially substantially reducing the frequency of shattering artifacts. Hence, it was anticipated that the contrast between the small-crystal concentrations indicated by the CAS probe with its inlet and the 2D-S instrument might be reduced compared to the TWP-ICE results presented by McFarquhar et al. (2007), where the CAS concentration typically exceeded CDP by approximately two orders of magnitude.

On the flights of 8 August, the aircraft sampled anvil cirrus over the ocean south of Costa Rica, and the DC-8 and WB57 pilots were instructed to successively fly through the same cloud at the same altitudes. Figure 2 shows a comparison between the CAPS (CAS and CIP) and 2D-S measurements from DC-8 and WB-57 flight legs at $\simeq 12 \mathrm{~km}$ and $\simeq 11.4 \mathrm{~km}$. The agreement between size distributions derived from the CIP and 2D-S imaging instruments is excellent throughout their overlapping size range $(>50 \mu \mathrm{m})$. The 2D-S measurements from the two aircraft agree reasonably well, particularly at sizes larger than $\simeq 150 \mu \mathrm{m}$. The WB-57 2D-S measurements indicate about 2-3 times as many smaller crystals than indicated by the DC-8 2D-S. This difference may be an indication of shattering off the leading edge of the WB57 wing affecting the 2D-S measurement at the wing-hatch location. Such artifacts would be spatially separated in the sheared flow between the wing leading edge and the instrument and would not be identified in the interarrival time analysis. The issue of shattering on the WB-57 wing affecting the 2D-S measurements under the wing is addressed further in the next section.

In contrast to the agreement between the imaging instruments, the CAS measurements indicate about an order of magnitude higher concentrations of small $(<50 \mu \mathrm{m})$ crystals than do the 2D-S measurements on the $12-\mathrm{km}$ DC-8 flight leg. At $11.4 \mathrm{~km}$, where more large crystals are present, the CAS concentrations are about two orders of magnitude higher than the 2D-S concentrations. Although there is more uncertainty in the 2D-S concentrations in the $10-30 \mu \mathrm{m}$ size range than at large sizes (due to depth of field uncertainties, statistical uncertainties resulting from small sample volumes, and uncertainties due to imperfect shattering removal), the CAS/2D-S discrepancy extends out to the maximum size limit of the CAS probe $(\simeq 50 \mu \mathrm{m})$. Comparisons between CAS and 2D-S on other flights indicate consistent results: when the natural concentration of small crystals is relatively low (i.e., a few hundreds per liter or less) as is the case most of the time in the anvil cirrus, and when the concentration of large ice is relatively high (order $0.001 \mathrm{~cm}^{-3}$ of $500 \mu \mathrm{m}$ crystals), the ratio of CAS/2D-S concentration measurements is typically 10 to 100 .

For comparison with the anvil cirrus measurements, we also show in Fig. 2 2D-S and CAPS measurements in drizzling stratocumulus sampled during a boundary-layer run at about $1 \mathrm{~km}$. In this case, there are relatively few large 

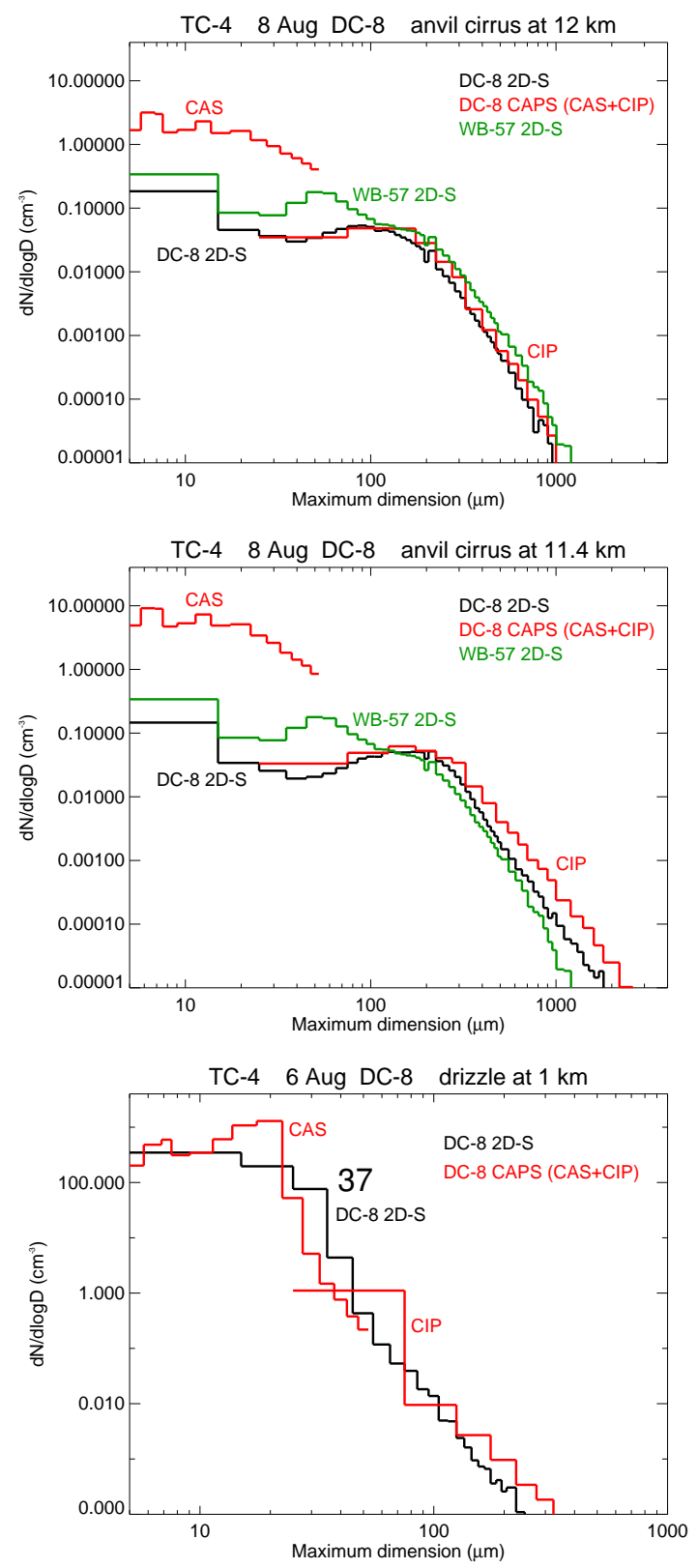

Fig. 2. Size distributions averaged over flight legs when WB-57 and DC-8 successively flew along the same flight legs at approximately $12 \mathrm{~km}$ (top) and $11.4 \mathrm{~km}$ (bottom) on 8 August are shown in the top two panels. The DC- 8 CIP distribution agrees well with the 2D-S distribution; however, the concentrations of small particles indicated by CAS are 1-2 orders of magnitude higher than indicated by $2 \mathrm{D}-\mathrm{S}$. For comparison with the anvil measurements, we show 2D-S and CAPS size distributions from measurements in drizzling stratotocumulus where shattering (or splashing) should have little impact and the small-droplet concentrations measured between the two probes are in reasonable agreement.

droplets and splashing should have a minimal impact on the measured concentrations of small droplets. In fact the interarrival time analysis used in the 2D-S data processing indi- cates very few splashing artifacts. Although there are some differences in sizing between CAS and 2D-S in the overlapping size range $(<50 \mu \mathrm{m})$, the concentrations are similar (particularly in contrast to the comparisons in anvil cirrus).

It is worth noting that in areas with relatively high natural small ice concentrations, effects of shattering on the CAS do not have as large a relative impact on ice concentrations as they do in regions with low natural ice concentrations. A simple example will explain why this result is expected: assume that a fixed mass of crystals large enough to generate shattering artifacts produces $1 \mathrm{~cm}^{-3}$ enhancement in the measured small-crystal concentration. If the natural concentration of small crystals were $0.1 \mathrm{~cm}^{-3}$, then the relative enhancement caused by shattering would be large (about an order of magnitude); whereas if the natural concentration of small crystals were greater than $1 \mathrm{~cm}^{-3}$, then the relative impact of shattering on measured ice concentration would be less important (about a factor of 2). This point is exemplified by comparison of the particle size distributions in Fig. 3, which shows CAPS and 2D-S measurements on 22 July in regions with high and low natural small ice abundance, in conjunction with approximately the same amount of large ice. Note, however, that the large ice only extends out to $500 \mu \mathrm{m}$, compared with 1 to $3 \mathrm{~mm}$ in Fig. 2. In Fig. 3, the 2D-S size distribution is shown with and without removal of shattering artifacts identified with the interarrival time analysis. In the presence of low natural ice, shattering increases the small ice concentration detected by the 2D-S probe by about an order of magnitude, and the CAS concentration is enhanced by as much as 2 orders of magnitude. In contrast, for the case with numerous natural small particles, shattering enhances the 2D-S small-crystal concentration by only a factor of 2, and the CAS measurements agree reasonably well with 2D-S. Although the number of shattered particles is on the order of $0.1 \mathrm{~cm}^{-3}$ in each case, the relative effect is much greater in the case with few natural small crystals. Note that the two regions are only $10 \mathrm{~km}$ apart near the top of aged anvil cirrus.

If the discrepancy between the CAS and 2D-S concentrations is caused by shattering on the CAS inlet, one would expect a correlation between the CAS/2D-S concentration ratio and the amount of large-ice mass available for shattering. Figure 4 shows that such a correlation does exist. For the three hours of anvil sampling on 8 August, the CAS/2D-S ratio and ice mass in crystals larger than $175 \mu \mathrm{m}$ are strongly correlated (Pearson correlation coefficient of 0.74 ). The ice water content is calculated from the 2D-S images using the area-to-mass parameterization described by Baker (2006). Our conclusion from this analysis is that even with the shroud removed, when the natural concentration of small crystals is on the order of $0.1 \mathrm{~cm}^{-3}$ or less and $500 \mu \mathrm{m}$ ice is at least about $0.001 \mathrm{~cm}^{-3}$, the small-particle concentrations indicated by the CAS probe appear to still be dominated by shattering artifacts. 

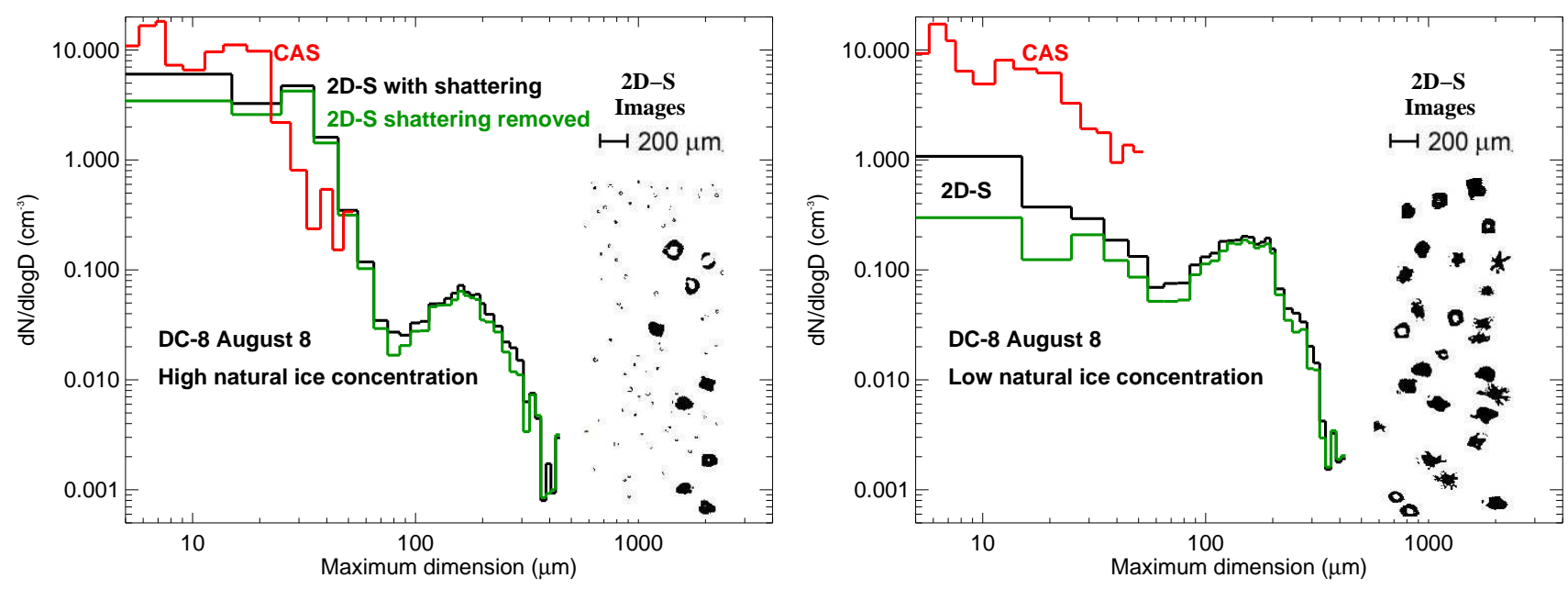

Fig. 3. CAPS and 2D-S size distributions (with and without shattering artifacts removed) are shown for two cases. Left panel: a case with numerous natural small crystals for which shattering has a relatively small impact on small-crystal concentration. Right panel: a case with low natural small-crystal concentrations for which shattering artifacts significantly affect the measurements.

\subsection{Small crystal concentration - large crystal mass cor- relations}

Another way to investigate the impact of ice crystal shattering artifacts is to examine the correlation between small- and large-crystal abundance. In convective updrafts or very fresh outflow, the concentration of both large and small crystals may be predominantly controlled by dilution of the cloud as ambient air is entrained, in which case the concentrations of small and large crystals will likely be correlated. On the other hand, as anvil cirrus ages, differential gravitational settling should separate the large and small crystals. One would expect to find places in the cloud where large crystals are present without small crystals and vice versa. For example, at the base of the cloud, the size distribution should be dominated by large crystals that sedimented from above, with relatively few small crystals present. Breakup of sublimating large ice crystals could produce some smaller fragments (Bacon et al., 1998), however this process would not likely produce large concentrations of small crystals. If the measured small-crystal concentration is dominated by shattering artifacts, we would expect to see a strong correlation between small and large crystal abundance in the measurement whenever large crystals are present, even in aged anvil cirrus, and even in precipitation zones where natural small crystals are actually absent. Assuming that the sizes of fragments generated by large-crystal shattering are roughly independent of the large-crystal size, the number of small fragments generated should be proportional to the total mass of large crystals that shatter. Such correlations were found in the CRYSTAL-FACE and other datasets (Heymsfield, 2007; McFarquhar et al., 2007).

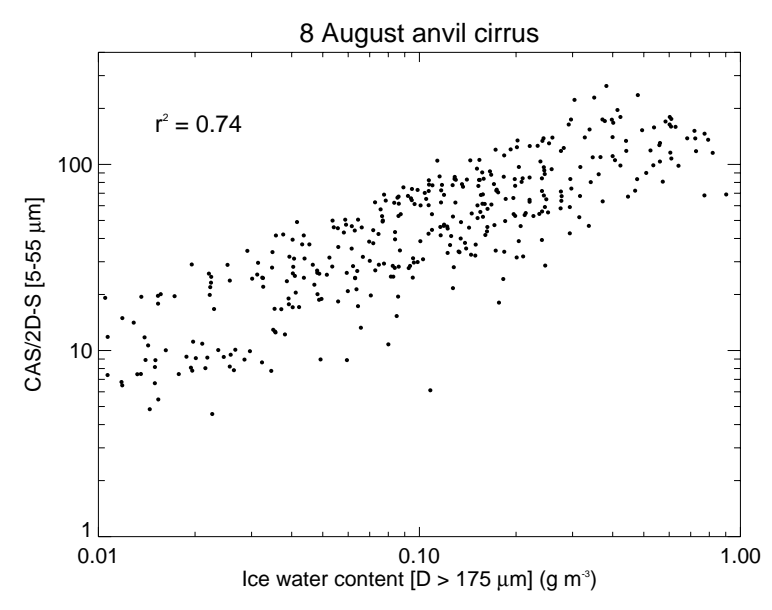

Fig. 4. Scatterplot of the DC-8 CAS/2D-S concentration ratio versus ice water content in large $(>175 \mu \mathrm{m})$ ice crystals in the anvil cirrus sampled on 8 August. The strong correlation suggests that the CAS concentrations are exaggerated as a result of shattering artifacts.

Scatterplots of measured small-crystal concentration versus large-crystal mass for the 8 August anvil cirrus are plotted in Fig. 5. Again, we restrict ourselves to the flight legs at 11.4 and $12 \mathrm{~km}$ such that the DC- 8 and WB-57 were sampling aged anvils with comparable crystal size distributions. For these plots, we have used the same size ranges for small $(10-55 \mu \mathrm{m})$ and large $(>120 \mu \mathrm{m})$ crystals for the different instruments. In the DC-8 CAPS dataset (Fig. 5a), smallcrystal concentration and large-crystal mass are strongly correlated throughout the aged anvil cirrus. Note also the very high concentrations of small crystals in the CAS data, 

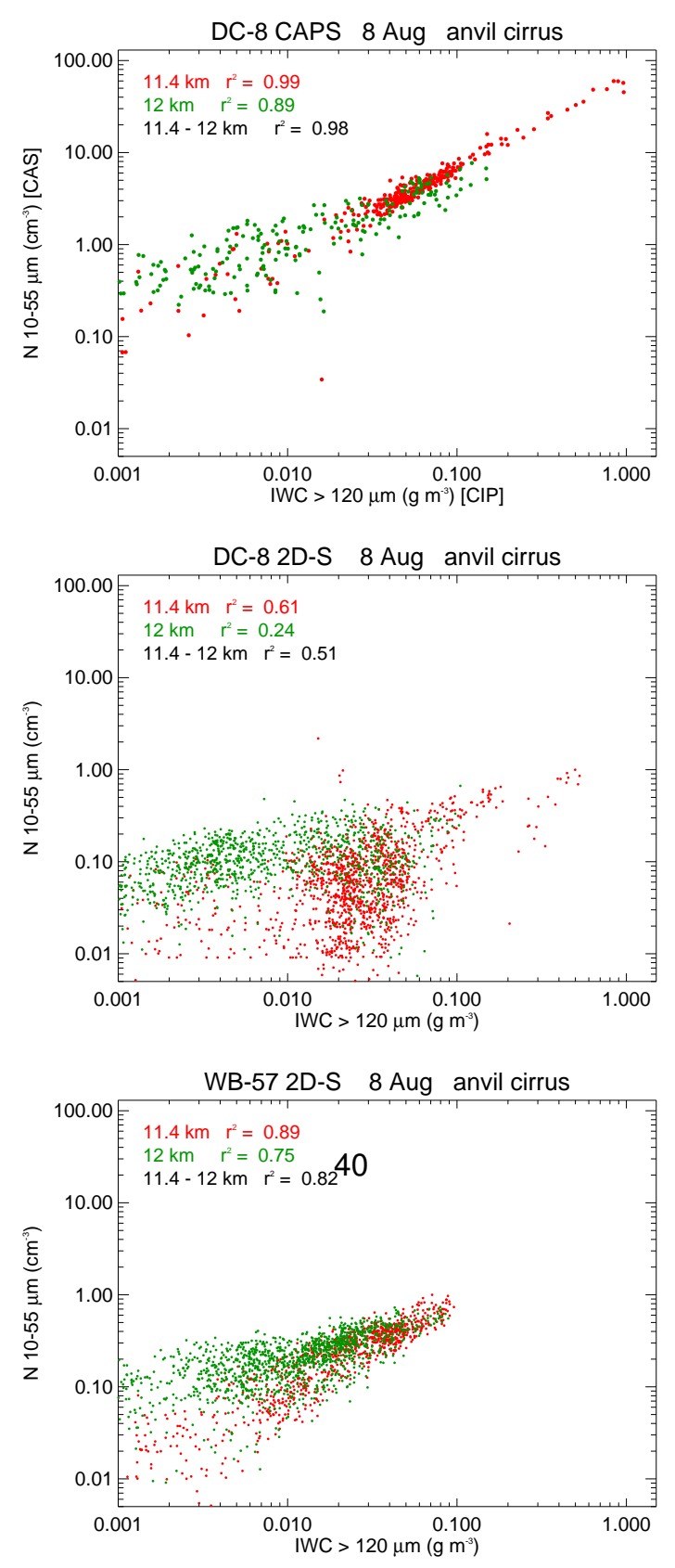

Fig. 5. Scatterplots of small-crystal concentration versus largecrystal mass are plotted for the 8 August anvil measurements. We restrict this analysis to the time periods when the DC- 8 and WB-57 were flying in the $11.4-12 \mathrm{~km}$ altitude range. The three panels correspond to measurements from the DC-8 CAPS, DC-8 2D-S, and WB-57 2D-S. Similar correlations are apparent in anvil cirrus sampled on other days. See text for discussion.

with values often exceeding $1 \mathrm{~cm}^{-3}$ and occasionally exceeding $10 \mathrm{~cm}^{-3}$. Similar strong correlations between smallcrystal concentration and large-crystal mass (not shown) are apparent in the CRYSTAL-FACE and TWP-ICE CAPS anvil cirrus datasets, again suggesting that, in the presence of large ice when the natural concentration of small crystals is relatively low, the small-crystal concentration measured by CAS is dominated by shattering artifacts.

In contrast, the DC-8 2D-S scatterplot (Fig. 5b) is more in line with what we would expect for aged anvil cirrus from physical considerations. There is a relatively weak correlation between small and large crystal abundance, and the dataset does include locations with plentiful large crystals but very few small crystals. Note also that the DC-8 2D-S small-crystal concentrations are much lower than the CAPS measurements suggest, with values only very rarely exceeding $1 \mathrm{~cm}^{-3}$.

Looking next at the WB-57 2D-S scatterplot (Fig. 5c), we see a stronger correlation between small-crystal concentration and large-crystal mass than apparent in the DC-8 2D-S dataset, as well as an absence of occurrences with considerable abundance of large crystals without numerous small crystals. As discussed above, it was recognized in the planning stages of TC4 that the mounting location of the 2D-S probe on the WB-57 was less than ideal. With the probe on a wing hatch toward the rear of the wing, there was a possibility of contamination from small-crystal fragments generated by large crystals impacting the wing leading edge and shattering. Fragments from wing leading edge shattering events cannot be readily removed by examining particle interarrival times, because the fragments get spatially separated in the sheared flow between the wing leading edge and the probe location $2 \mathrm{~m}$ back on the wing. This analysis suggests that such contamination may indeed have affected the WB-57 2D-S size distribution measurements. To be sure the 2D-S results presented are not contaminated by shattering artifacts, in the remainder of this paper we will, unless otherwise noted, focus on the DC-8 2D-S measurements. We emphasize that the problem of apparent shattering artifacts in the WB-57 2D$S$ data is an airframe and mounting location problem rather than an instrument problem.

\subsection{Quantifying shattering artifacts}

The comparisons shown above suggest that shattering of large crystals can be a large source of artifacts in the CAS measurements. Field et al. (2003) and Field et al. (2006) provided a quantitative measures of the impact of shattering on FSSP and imaging probes (e.g., 2D-C) measurements, respectively, by reporting the ratio of measured ice concentrations to those with shattering artifacts removed (using interarrival times). However, this approach does not allow users of other FSSP datasets to estimate the concentration of shattering artifacts under different conditions. As discussed above, the relative impact of shattering will depend both on the number artifacts and the concentration of natural small crystals. For example, Arctic mixed-phase clouds have much lower natural ice concentrations (typically a few per liter; Fridlind et al., 2007) than anvil cirrus (typically on the order of $0.1 \mathrm{~cm}^{-3}$ ). Thus, the relative impact of shattering on 
ice concentrations measured by $2 \mathrm{D}-\mathrm{S}$ probes may be much more severe for the Arctic clouds than indicated by Field et al. (2006) for anvil cirrus.

As a means of quantifying the effect of shattering on the CAS measurements, we present here the correlation between spurious CAS concentration and the 2D-S large-crystal mass. We have selected averaging periods with reasonably homogeneous cloud conditions by applying the following criteria: (1) continuous cloud sample of at least $10 \mathrm{~s}$, (2) 2D-S concentration $>50 \mu \mathrm{m}$ to remain within 0.5 and 1.5 times the average concentration over the averaging period, (3) 2D-S concentration $<50 \mu \mathrm{m}$ to remain within 0.5 and 1.5 times the average concentration over the averaging period, and (4) average concentrations of $2 \mathrm{D}-\mathrm{S}$ particles $>50 \mu \mathrm{m}$ to be $>10^{-6} \mathrm{~cm}^{-3}$. We also exclude time periods for which the CAS concentration is less than 10 times greater than the $2 \mathrm{D}-\mathrm{S}$ concentration over their overlapping size range $(\simeq 12-$ $50 \mu \mathrm{m})$ such that the discrepancy between CAS and 2D-S can be assumed to be shattering artifacts. Using these restricted datasets for different flights, we compute linear leastsquares regression fits.

The resulting scatterplots of spurious CAS $(>12 \mu \mathrm{m})$ concentration, extinction, and IWC versus $2 \mathrm{D}-\mathrm{S}$ IWC and the linear fits are shown in Fig. 6 for anvil cirrus sampled on the flight of 5 August. With the dataset restricted to the relatively homogeneous time segments, the correlations are excellent (e.g., a Pearson correlation coefficients $>0.97$ ). It should be noted that the slope of the correlations varies significantly from flight to flight, and the fits presented in Fig. 6 should be taken as a very rough guide to the quantitative impact of shattering on the CAS probe.

\section{Implications of evidence for shattering artifacts}

The evidence presented here suggests that small-crystal concentrations measured by the CAS probe (with or without the shroud in front of the inlet) are dominated by shattering artifacts when large crystals are present and natural smallcrystal concentrations are relatively low. The great majority of the anvil cirrus measurements made during CRYSTALFACE had considerable amounts of large ice, and thus, when the natural small ice concentration is relatively low, the CAS concentrations were probably dominated by shattering artifacts, as they appear to be in the TWP-ICE and TC4 anvil cirrus datasets. Garrett et al. (2005) analyzed CRYSTAL-FACE CAPS data and concluded that in anvil cirrus sampled on 21 July 2002, crystals smaller than $50 \mu \mathrm{m}$ dominated the size distributions and radiative properties. Baumgardner et al. (2005) used CRYSTAL-FACE CAS data to infer habits of small crystals, and Chepfer et al. (2005) compared remotesensing retrievals of ice crystal habits in CRYSTAL-FACE anvil cirrus with habit information retrieved from CAS measurements. We suggest that the conclusions of these studies should be revisited given the likelihood that CAS was often
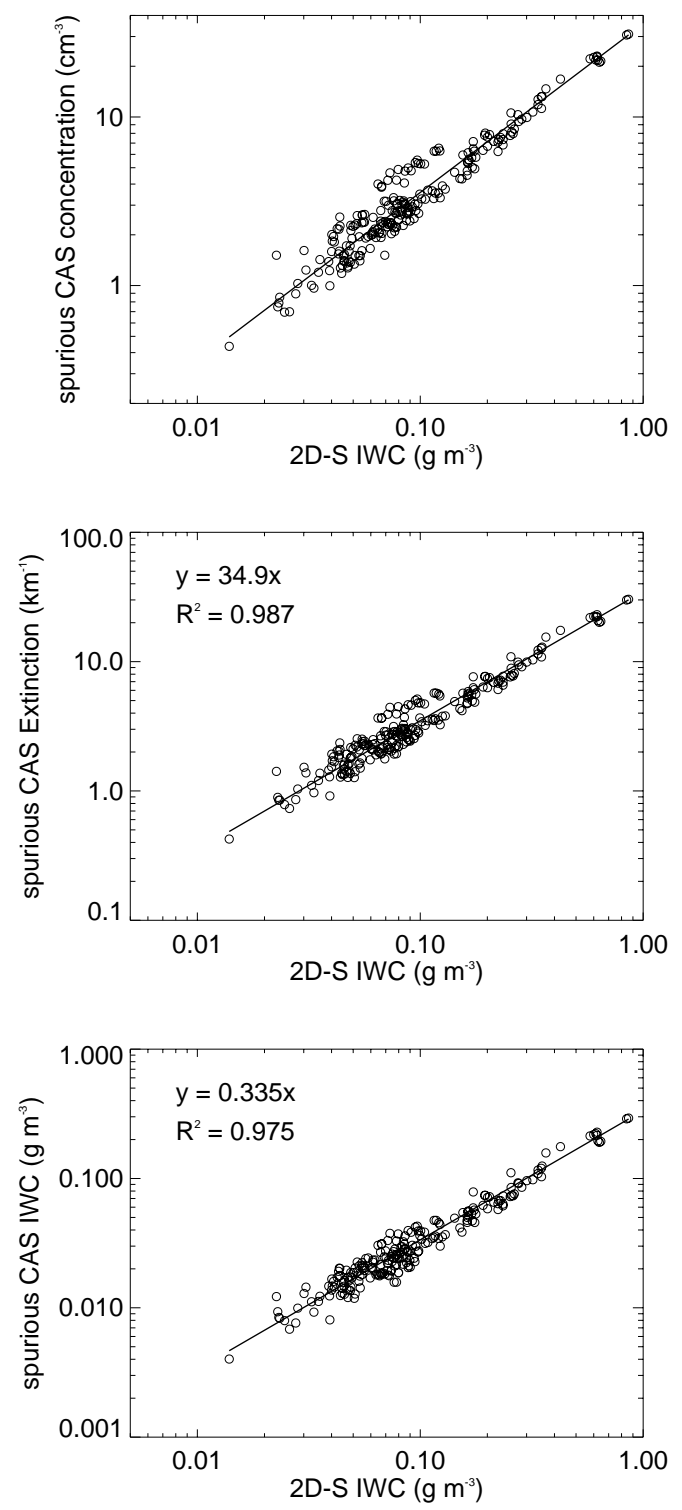

Fig. 6. Scatterplots of spurious CAS concentration (top), extinction (middle), and and IWC (bottom) $(11-50 \mu \mathrm{m})$ versus $2 \mathrm{D}-\mathrm{S}$ ice water content for time segments with relatively homogeneous clouds (see text). The lines shown are linear least-squares regression fits, and the slopes are given in the legends. We caution that these correlations should be taken as very approximate estimates to the magnitude of shattering artifacts that might be seen in other clouds sampled with CAS.

primarily measuring shattering artifacts in the anvil cirrus. The WB57 Mid Latitude Cirrus Experiment (MIDCIX) included sampling of a wide range of midlatitude cirrus types, some of which may have been sufficiently lacking in large crystals such that the CAS data may be valid, and some of which may have been contaminated by shattering. In any case, we suggest these datasets should be used with caution. 
The indications of shattering contamination in the TC4 CAS measurements, with the shroud removed, may have even broader implications. The CAS probe without the shroud has an inlet geometry very similar to the FSSP instruments used for the past two decades to measure ice crystal size distributions in cirrus, including tropical anvil cirrus. However, direct comparisons between FSSP and instruments such as 2D-S and CDP, along with use of FSSPs with interarrival times recorded, are required to further evaluate under what conditions the historical dataset can be relied upon. Nevertheless, the evidence presented here suggests that, in general, it would seem prudent to be suspicious of ice crystal concentrations inferred from any probes with inlets or surfaces protruding into the airstream (without the use of interarrival times to identify and remove shattering artifacts), including CVIs, whenever large crystals are present.

Fridlind et al. (2004) used CRYSTAL-FACE CAPS measurements in subtropical anvil cirrus as evidence for the predominance of free-tropospheric aerosols entrained into the deep convective updrafts (rather than boundary-layer aerosols in the inflow region) for production of ice crystals that ultimately get detrained into the anvils. Cloud-resolving model simulations were run with all aerosols in the vertical column, with aerosols above $6 \mathrm{~km}$ removed, and with aerosols above $2 \mathrm{~km}$ removed. Only when all aerosols in the vertical column were included did the simulations reproduce the size distributions measured by CAPS in the upper parts of the anvils, with a distinct mode in the number distribution at around 20-30 $\mu \mathrm{m}$ and very large concentrations of small crystals. If aerosols above $2 \mathrm{~km}$ were removed in the simulation, the mode in the number distribution shifted out to $\simeq 60 \mu \mathrm{m}$, and the small crystals were largely absent. However, given the results presented by McFarquhar et al. (2007), the results presented here, and the fact that, in general, there were considerably more large crystals in the CRYSTAL-FACE anvil cirrus than in the cirrus sampled during TWP-ICE and TC4, it seems very likely that the smallcrystal mode in the CAPS data was strongly influenced by shattering artifacts.

Although other lines of evidence for the predominance of mid-tropospheric aerosols were presented by Fridlind et al. (2004) involving measurements made in a mixed-phase region of a convective updraft, the key issue of interest for the impact of cumulonimbus clouds on climate is what controls the size distribution of ice crystals detrained into the anvil cirrus. If the CAPS small-crystal concentrations are indeed dominated by shattering artifacts, then one must conclude that the agreement between the simulated ice crystal size distribution with the CAPS distributions indicates the simulated anvil had excessive numbers of small crystals. There are a number of physical processes in the model, such as entrainment and ice crystal aggregation, that are not well constrained, and misrepresentations of these processes might well result in excessive ice concentrations. The spatial resolution $(500 \mathrm{~m})$ used in the simulations is inadequate for re- solving the eddies that dominate entrainment into convective updrafts. An experiment was done with $250 \mathrm{~m}$ spatial resolution, but even finer resolution may be required.

Other evidence from the CRYSTAL-FACE mission points to the possibility that anvil ice crystals predominantly originated from aerosols in the lowermost troposphere. Cziczo et al. (2004) analyzed the chemical composition of residual aerosols from anvil ice crystals. They found that $70 \%$ of the residual particles were sea salt, mineral dust, or fly ash. None of these particle types were present in significant concentrations in clear free-tropospheric air, suggesting the source was the planetary boundary layer. It should be noted that this analysis only included residual particles larger than about $0.2 \mu \mathrm{m}$ diameter, and smaller aerosols probably contribute significantly to droplet activation in strong cumulonimbus updrafts. Twohy and Poellot (2005) analyzed residual particles larger than $0.1 \mu \mathrm{m}$ collected with a counterflow virtual impactor. They found that about $37 \%$ of the small residual nuclei and $49 \%$ of the large residual nuclei were either sea salt or industrial particles, again suggesting a strong dependence of anvil ice concentrations on boundary-layer aerosols. This discussion underscores the fact that accurate measurements of ice crystal size distribution are required for evaluation of aerosol impacts on cirrus microphysical properties and radiative effects.

\section{Contribution of small crystals to tropical anvil cirrus radiative properties}

As discussed above, past measurements using instruments with inlets have generally indicated that small crystals often dominate, or at least contribute significantly to, the surface area density (and accordingly, extinction) in cirrus clouds. Here, we present several cases from the TC4 mission using 2D-S data that suggest, at least for the anvil cirrus sampled during this mission, small crystals contribute relatively little to the extinction.

An unprecedented level of aircraft coordination was achieved during TC4, with the ER-2 and either one or both of the WB-57 and DC-8 aircraft flying in a stacked formation for many hours on several flights. During much of the coordinated-flight time, the WB-57 and DC- 8 were flying in the anvil cirrus. Besides providing a great deal of in situ data for comparison with cloud remote-sensing retrievals from various instruments on the ER-2, the aircraft coordination also allows us to use the remote-sensing information to provide context for the in situ measurements. In particular, we can tell where the aircraft measurements were made relative to cloud top and cloud base.

For cases with significant periods of good aircraft coordination, we present the merged ER-2 Cloud Physics Lidar (CPL) and Cloud Radar System (CRS) product time curtain (i.e., retrieved cloud property versus time and height along the ER-2 flight track), and we indicate on these curtain 

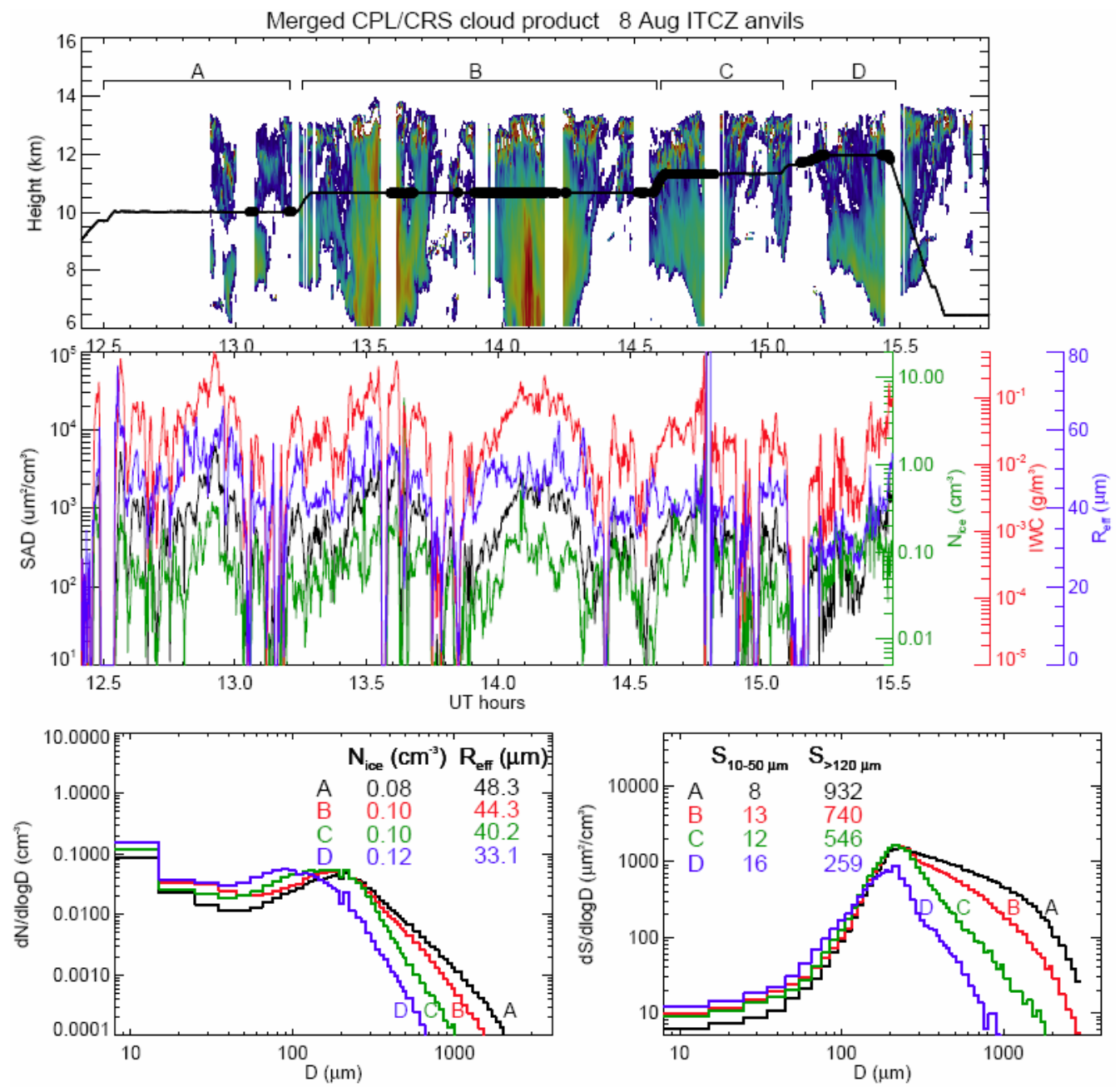

Fig. 7. Top panel: curtain plot the backscatter derived from a combination of the ER-2 CPL and CRS measurements versus time and height. The black trace indicates the altitude of the DC-8 flying below the ER-2; where the altitude trace is thick, the horizontal separation between the DC- 8 and ER-2 was less than $5 \mathrm{~km}$. Middle plot: time series of surface area density, ice concentration, ice water content and effective radius, all derived from the $2 \mathrm{D}-\mathrm{S}$ measurements. Bottom plots: number and surface area distributions averaged over the four constantaltitude flight legs indicated in the top panel. Leg averaged ice concentrations, effective radii, small-crystal (10-50 $\mu \mathrm{m})$ surface area density and large-crystal $(>120 \mu \mathrm{m}) \mathrm{SAD}\left(\mu \mathrm{m}^{2} \mathrm{~cm}^{-3}\right)$ are indicated in the legends.

plots the altitude of the DC-8 flying below the ER-2. The merge product contains coincident vertical curtains of CPL backscatter and CRS reflectivity, which when combined, gives the full vertical cloud distribution not attainable with either instrument alone. Merged signal images contain normalized values $(0-1)$ of lidar backscatter ratio using the log of the ratios from 0.5 to 500.0 and normalized values $(0-1)$ of radar reflectivity (dBZ) using the range -30 to $20 \mathrm{dBZ}$. The type of signal making up the cloud parcels (i.e., CPL, CRS, or both) is also tracked. Next, we present time series of bulk cloud properties calculated from the 2D-S measurements. Lastly, for time periods indicated on the CPL/CRS curtain plots, we present averaged 2D-S number and surface area density distributions. The average contributions to total projected surface area density (SAD) from small $(10-50 \mu \mathrm{m})$ and large $(>120 \mu \mathrm{m})$ crystals, as well as the average ice concentrations and effective radii, are given in legends on these plots. We use the standard definition of effective radius here:

$R_{\text {eff }}=\frac{3 \mathrm{IWC}}{2 \beta_{\mathrm{ext}} \rho_{i}}$,

where IWC is the ice water content, $\beta_{\text {ext }}$ is the extinction, and $\rho_{i}$ is the bulk ice density $\left(0.9 \mathrm{~g} \mathrm{~cm}^{-3}\right)$.

We begin with the anvil cirrus sampled over the eastern Pacific, south of Costa Rica by the DC- 8 and ER-2 on 8 August (Fig. 7). On this day, we achieved the greatest degree of aircraft coordination, with the aircraft vertically stacked (to within $5 \mathrm{~km}$ horizontal separation) for long time periods. As indicated by the altitude trace on the CPL/CRS curtain plot, for most of the anvil-sampling time period, the DC-8 

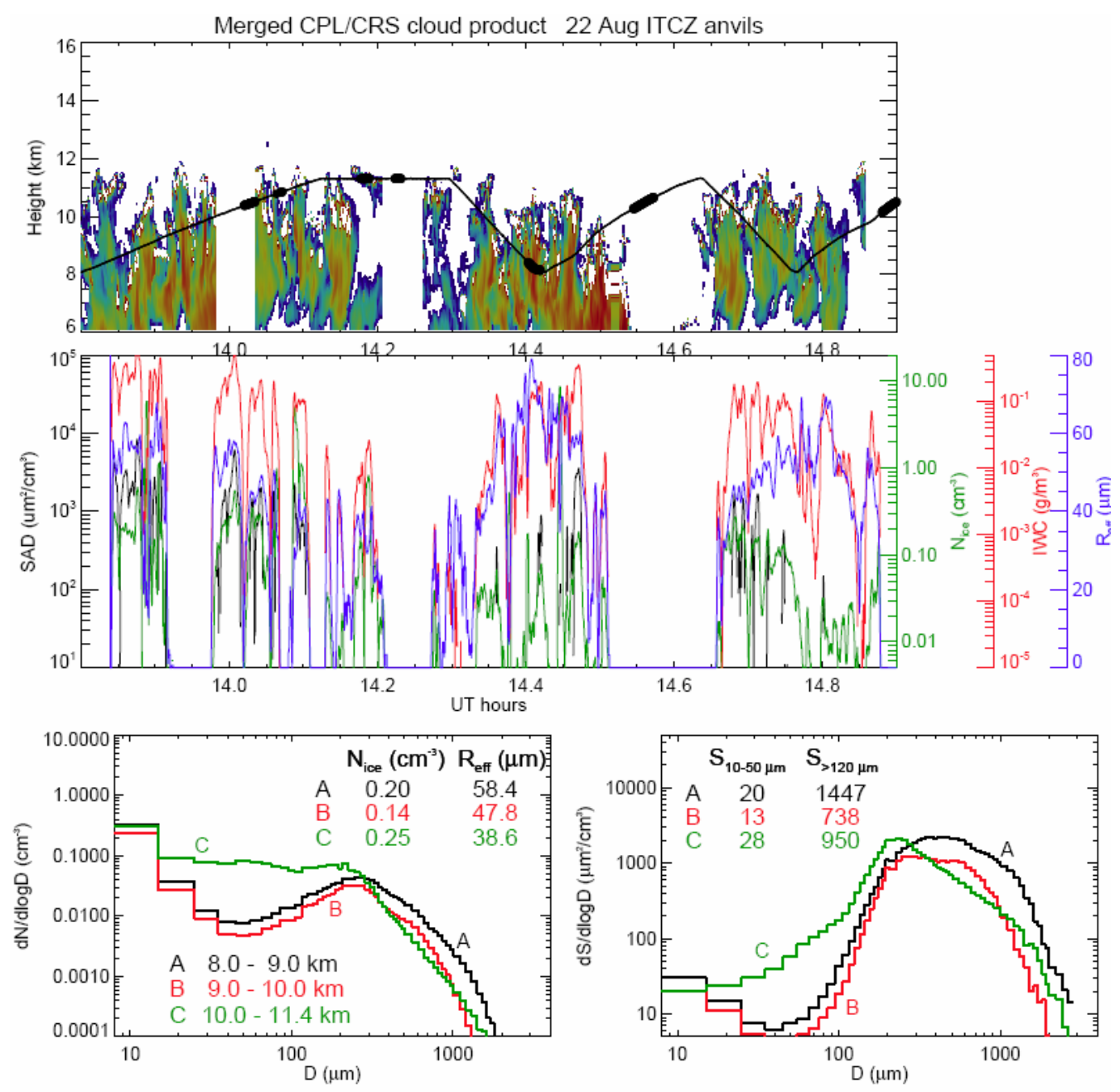

Fig. 8. As in Fig. 7, but for anvil cirrus generated by relatively weak ITCZ convection sampled on 22 July. Since the flight pattern primarily consisted of ascents and descents through the clouds, we present size distributions averaged over altitude ranges rather than time periods.

was well below the cloud top altitude of $13-13.5 \mathrm{~km}$. Also, the clouds generally extended at least a few km below the DC-8 flight altitude. Only on the last leg at $\simeq 12 \mathrm{~km}$ was the DC-8 near cloud top. The time series plot shows the large degree of variability typically observed in cirrus. The anvil cirrus sampled on this flight was generally relatively aged, with ice water contents less than $0.2 \mathrm{~g} \mathrm{~m}^{-3}$ and total ice concentrations typically on the order of $0.1 \mathrm{~cm}^{-3}$ and almost never exceeding $1 \mathrm{~cm}^{-3}$. The size distributions averaged over the four constant-altitude flight segments indicate clear evidence of gravitational size sorting in the anvils, with fewer large crystals and more small crystals as one ascends higher in the anvils. Ice crystals smaller than $55 \mu \mathrm{m}$ contribute very little (less than 6\%) to the total surface area density at any vertical level in the anvils.

The effective radii derived from $2 \mathrm{D}-\mathrm{S}$ ice water content and extinction range from about 30 to $60 \mu \mathrm{m}$ deep in the cloud, but are limited to about $30-35 \mu \mathrm{m}$ near cloud top.
These cloud-top effective radii are in good agreement with a variety of remote-sensing retrievals, including MAS, MODIS (Hong et al., 2007), and the Solar Spectral Flux Spectrometer (SSFR) (P. Pilewskie, personal communication, 2008). Note that we are not arguing that this comparison with remotesensing measurements serves as strong evidence for the accuracy of the 2D-S measurements. The uncertainties in remotesensing retrievals of cloud properties and considerable and difficult to quantify, precluding their use as a baseline for evaluating other measurements. We simply note the consistency between the different measurements.

We next present the measurements made in outflow anvils from typical eastern-Pacific ITCZ convection on 22 July (Fig. 8). In this case, the cloud tops were near the DC-8 maximum altitude, and the aircraft sampled from cloud top (about $11.5 \mathrm{~km}$ ) down to about $8 \mathrm{~km}$ in a "saw-tooth" pattern. The height dependence of effective radius is evident; for example as the aircraft descends during the 14.3-14.4 UT 

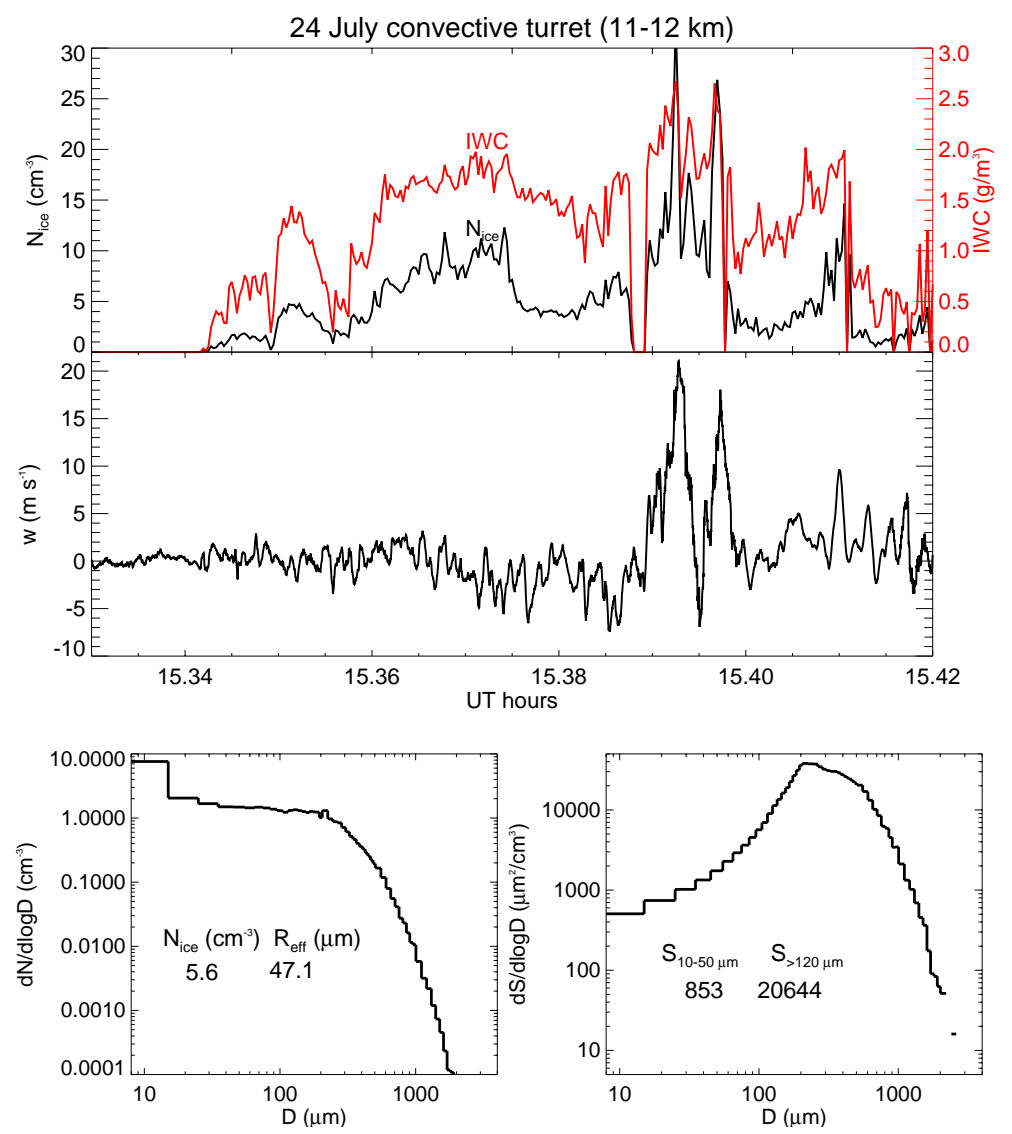

Fig. 9. Time series of ice concentration, and IWC (top panel) and vertical wind speed (middle panel) are shown for an active turret sampled on 24 July. Number and surface area distributions are shown in the bottom panels.

time period from about 12 to $8 \mathrm{~km}, R_{\text {eff }}$ increases from about $30-40$ to nearly $80 \mu \mathrm{m}$. The size distributions (in this case averaged over height ranges) again show the vertical size sorting and the limited contribution of small crystals to SAD.

On the DC- 8 flights of 22 and 24 July, very fresh outflow from anomalously strong ITCZ convection was sampled, as well as the tops of active turrets at $11-12 \mathrm{~km}$. Figure 9 shows time series and size distributions in the strongest convection sampled on 24 July. Remote-sensing data from the ER-2 is not shown for this case because we did not have close aircraft coordination; however, the nadir viewing Second Generation Precipitation Radar (APR-2) (Sadowy et al., 2003) on the DC- 8 provides information about the convective system structure and dynamics below the aircraft. Imagery from the APR-2 on board the DC- 8 is shown in Fig. 10. The DC- 8 first flew over a portion of aged outflow followed by a very extensive region of active convection including four well defined convective cells (U1-U4) and a wide transitional area (T). Of the four active cells, U2 was the most developed vertically, with the peak of vertical wind estimated at around $17 \mathrm{~ms}^{-1}$ at $9 \mathrm{~km}$ (the top of the visible range for the radar), large partially frozen hydrometeors lofted at least to $8 \mathrm{~km}$, and a couplet downdraft at lower levels, suggesting that this cell was in the late stages of maturity. The last cell (U4) shows a region of maximum updraft at about $8.5 \mathrm{~km}$ with numerous large hydrometeors peaking at $5.5 \mathrm{~km}$, the absence of a downdraft and relatively depleted volume underneath suggest that this cell was at a younger stage than $\mathrm{U} 2$.

Ice concentrations (Fig. 9) in this cloud were extremely high (average values of $5.3 \mathrm{~cm}^{-3}$ and a peak value of $32 \mathrm{~cm}^{-3}$ ). Even with these very large numbers of small crystals present, the surface area density is still dominated by large crystals, with crystals smaller than $55 \mu \mathrm{m}$ contributing less than 5\% to the total SAD. It is also interesting that the mean effective radii in these events $(\simeq 47 \mu \mathrm{m})$ are somewhat larger than found in the tops of mature anvil cirrus $(\simeq 30$ $40 \mu \mathrm{m})$. This observation attests to the ability of the strong updrafts $\left(20 \mathrm{~m} \mathrm{~s}^{-1}\right.$ at $\simeq 12 \mathrm{~km}$ ) to loft large ice crystals (graupel) into the upper troposphere.

The measurements presented here suggest that smallcrystal concentrations decrease dramatically, from up to $30 \mathrm{~cm}^{-3}$ in turrets, to a few $\mathrm{cm}^{-3}$ in fresh outflow, to $\leq 0.1 \mathrm{~cm}^{-3}$ in anvil cirrus with ages ranging from about 30 min to a few hours. It might seem counterintuitive that as anvil cirrus ages and larger crystals sediment, the upper parts of the anvil don't appear to become increasingly dominated 

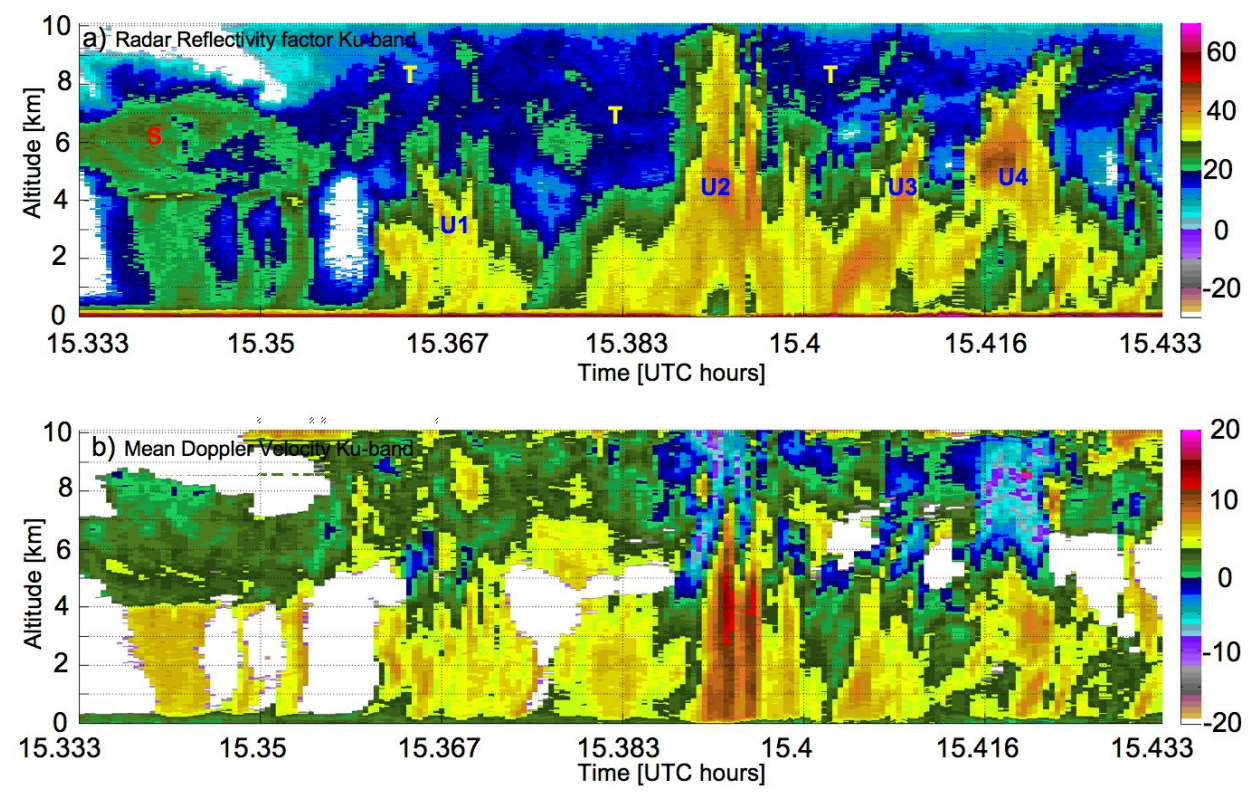

Fig. 10. Imagery from the APR-2 radar showing reflectivity (top) and Doppler velocity (bottom). See text for discussion.

by small crystals. However, other physical processes, such as sublimation, deposition growth, and aggregation, tend to decrease the small-crystal concentration as the cloud ages. In particular, in moderately subsaturated (supersaturated) air crystals will sublimate (grow) rapidly through the smallcrystal size range (Fig. 11). Ice saturation ratio measurements in the TC-4 anvil cirrus typically indicate a great deal of variability with values ranging between about 0.8 to 1.2 . Under such conditions, small crystals will either sublimate completely or grow out of the small-crystal size range on time scales of about 10-60 min. The measurements indicating a lack of small crystals suggest that these sinks for small crystals likely dominate over any potential sources of small crystals (e.g., nucleation of new crystals in supersaturated regions) in the aging anvils.

The calculations presented in Fig. 11 assume a range of values for the deposition coefficient. If the value is much smaller than 0.1 , as suggested by a recent laboratory measurement (Magee et al., 2006) $\left(\alpha_{\mathrm{dep}} \approx 0.006\right)$, then the small crystals could persist for hours even with moderate subsaturation or supersaturation (Fig. 11). Past studies comparing numerical simulations and measurements of ice concentrations in wave clouds and synoptic cirrus have suggested that the deposition coefficient cannot be much less 0.1 (Jensen et al., 1998; Comstock et al., 2008). The fact that the small crystals do not persist in the anvil cirrus is also inconsistent with deposition coefficients smaller than 0.1 , which would prevent $10-50 \mu \mathrm{m}$ crystals from growing or sublimating rapidly.

Since small crystals contribute very little to extinction in the anvils, it seems unlikely that they affect other radiative properties, such as radiative forcing and radiative heating. In

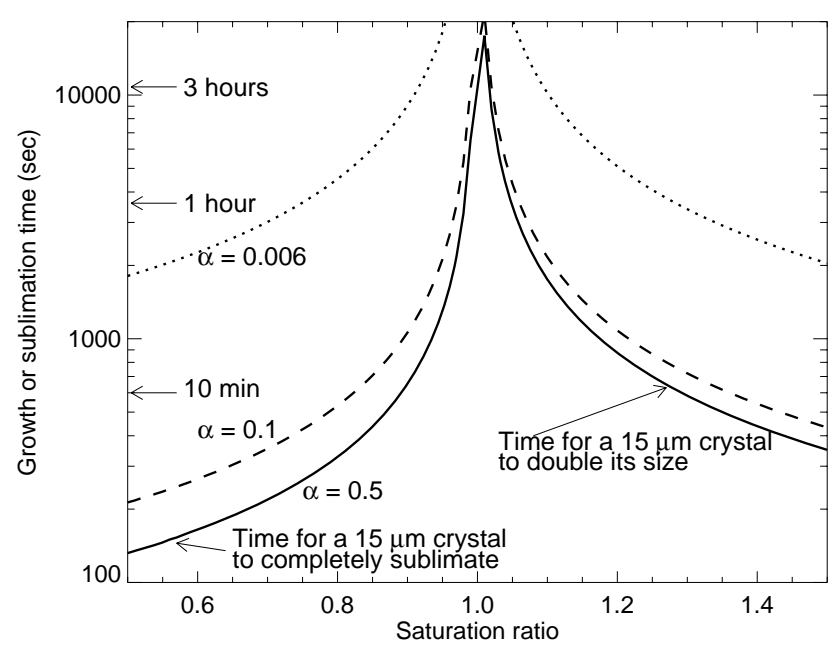

Fig. 11. The times required for an ice crystal to either completely sublimate (in subsaturated air) or double it's size (in supersaturated air) plotted versus ice saturation ratio for three different assumed deposition coefficients. These calculations assumed a temperature of $220 \mathrm{~K}$ and a pressure of $200 \mathrm{hPa}$. Spherical particle growth is assumed. Given the relative humidity variability typically observed in anvil cirrus, the fact that the plentiful small crystals detrained from convection do not persist is inconsistent with deposition coefficients much less than $\simeq 0.1$.

order to confirm this hypothesis, we have run radiative transfer calculations with cloud properties specified based on the 2D-S measurements. We use the 8 August DC- 8 and WB-57 2D-S measurements to construct ice crystal size distributions versus height (Fig. 12). As discussed above, there is evidence that the WB-57 2D-S concentrations of small crystals 
are exaggerated because of shattering on the wing leading edge. As a result, we may be overestimating the effects of small crystals in our calculations. We use a two-stream radiative transfer model (Toon et al., 1989) with the temperature and water vapor profiles specified based on the DC-8 dropsonde at 12.89 UT. Mie scattering is used to calculate the cloud single-scattering properties.

Figure 13 shows the top-of-atmosphere solar, infrared, and net radiative forcing versus the minimum ice crystal size included in the calculation. For example, the radiative forcing values at $50 \mu \mathrm{m}$ on the abscissa were calculated using only crystals in the size distribution larger than $50 \mu \mathrm{m}$. It turns out that the solar and infrared radiative forcings are approximately equal and opposite in this cloud, resulting in a near zero net forcing. As the minimum size included increases, the magnitudes of both the solar and infrared forcings decrease, with solar forcing decreasing faster, resulting in a slight increase in net forcing. However, the bottom line is that ice crystals smaller than $50 \mu \mathrm{m}$ contribute very little to the solar, infrared, or net forcing. Figure 14 shows cloud radiative heating rate profiles from the same calculations, both including and excluding crystals smaller than $50 \mu \mathrm{m}$. As expected the small crystals also contribute very little to radiative heating in the anvil.

Anvil cirrus sampled on several additional days indicate similar general features to the cases shown above: increasing effective radius with decreasing height in the anvils and very little contribution of small crystals to SAD (i.e., extinction). With the exception of the active turrets sampled on 22 and 24 July and the isolated cases discussed below, we generally do not see regions with elevated ice concentrations that would be indicative of local nucleation events within the anvils. In other words, the anvils sampled during TC4 seems to be controlled by dissipation and sedimentation of ice detrained from the deep convection, without evidence for significant regeneration of ice crystals downwind from the convection.

On at least two flights (22 July and 8 August), isolated occurrences of high ice concentration $\left(>1 \mathrm{~cm}^{-3}\right)$ were indicated by the 2D-S data in aged anvil cirrus far away from any active convection. On each of these flights there are a few brief periods $(<1 \mathrm{~min}$ of flight time $\simeq 1.2 \mathrm{~km}$ distance) with ice concentrations exceeding $1 \mathrm{~cm}^{-3}$ and sometimes approaching $10 \mathrm{~cm}^{-3}$. Nitric oxide, carbon dioxide, and aerosol measurements made on the DC- 8 give no indication that these events were aircraft contrails.

One of these high ice concentration events occurred near cloud top allowing us to use the ER-2 remote-sensing measurements to investigate the cloud. Figure 15 shows a time series of ice concentration and vertical wind speed measured on the DC-8 for this event. The $\simeq 1-3 \mathrm{~m} \mathrm{~s}^{-1}$ vertical wind oscillations suggest the possibility of a gravity wave in the region with elevated ice concentration. The corresponding MAS image and effective radius retrievals (for the same time period as shown in Fig. 15. (Fig. 16) also indicates somewhat of a wave structure in the cloud. However, the cloud struc-

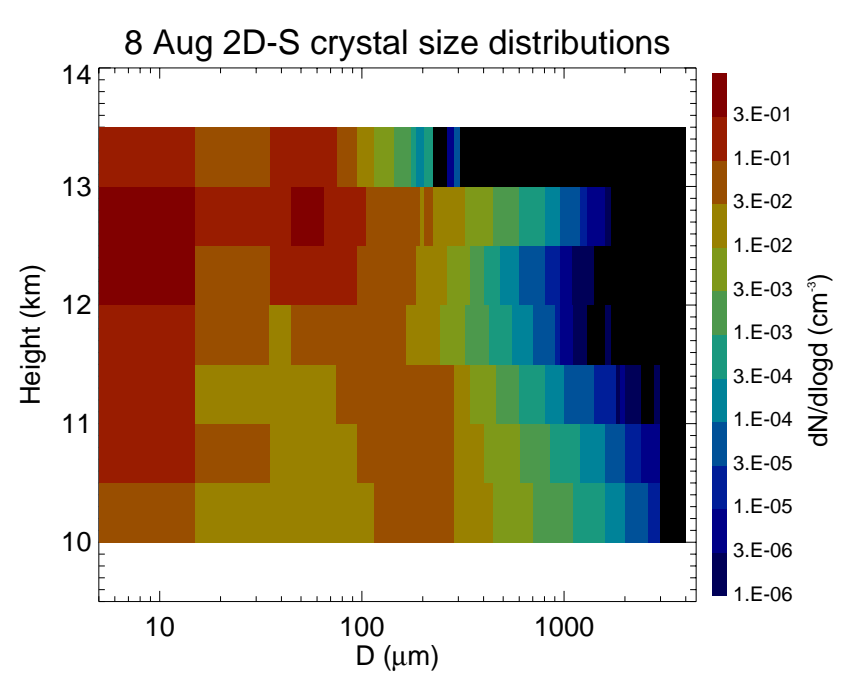

Fig. 12. Ice crystal size distributions in $1-\mathrm{km}$ altitude bins constructed from the 8 August DC-8 and WB-57 2D-S anvil cirrus measurements.

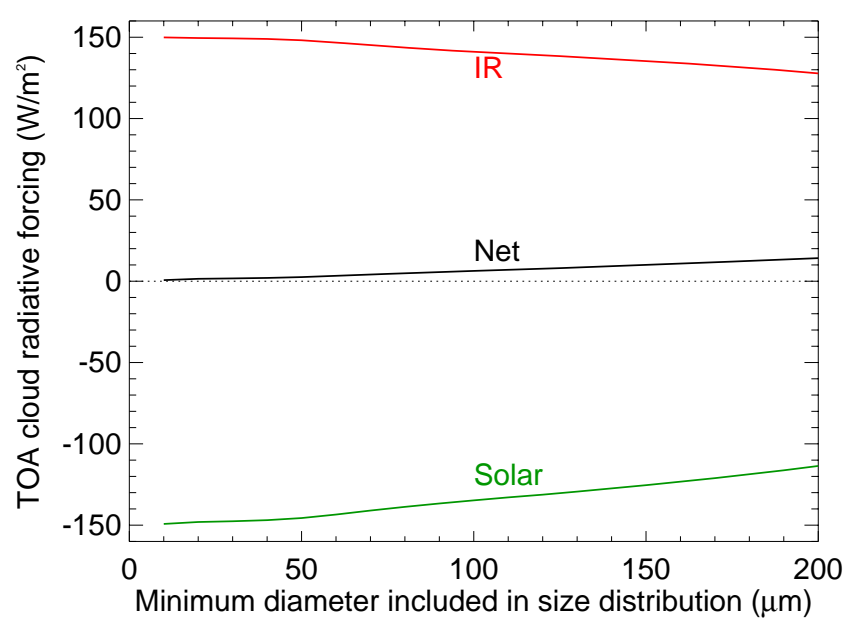

Fig. 13. Solar, infrared, and net top-of-atmosphere cloud radiative forcings are plotted versus the minimum size included in the ice crystal size distributions. Incrementally excluding small crystals up to a larger and larger size decreases both solar and infrared forcing, with a slight increase in net forcing. Small $(D<50 \mu \mathrm{m})$ contribute very little to radiative forcing.

ture looks more like small-scale convection than purely laminar flow in a wave. The MAS effective radius retrieval indicates very small ice crystals $\left(r_{e}<12 \mu \mathrm{m}\right)$ collocated with the high ice concentrations indicated by the 2D-S measurements. The 2D-S effective radii are also considerably smaller in the region with enhanced ice concentration than in surrounding regions. The likely explanation for the high ice concentrations is homogeneous freezing of aqueous aerosols resulting from rapid cooling either in gravity waves or convective updrafts. 


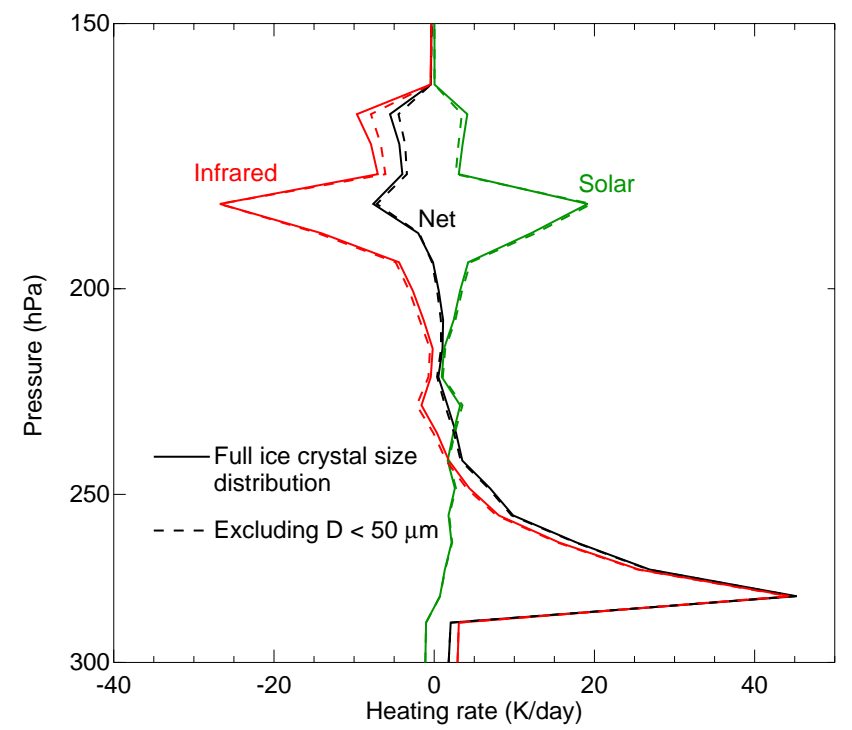

Fig. 14. Solar, infrared, and net cloud radiative heating rate profiles are plotted from calculations including all crystal sizes (solid) and excluding crystals smaller than $50 \mu \mathrm{m}$ (dashed). The small crystals have negligible impact on radiative heating.

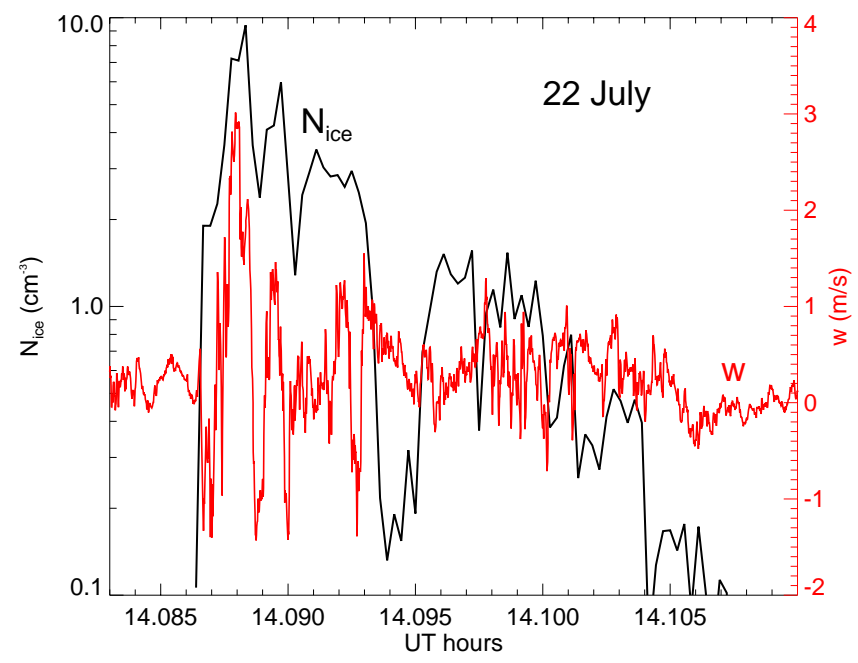

Fig. 15. Time series of vertical wind speed measured by MMS (red) and 2D-S ice concentration (black) in a region with high ice concentrations apparently caused by convection or gravity waves.

We emphasize here that these high ice concentration events are very rare in the aged anvil cirrus sampled in TC4. The vast majority of the TC4 2D-S ice concentration measurements in anvil cirrus indicated values between about 0.01 and $0.4 \mathrm{~cm}^{-3}$ (Fig. 17). In fact values exceeding $1 \mathrm{~cm}^{-3}$ occurred less than $1.4 \%$ of the time in anvil cirrus. As a result, the enhanced ice concentration events probably had little impact on either the anvil radiative properties or persistence.

\section{Summary and Discussion}

The TC-4 microphysics dataset provides multiple lines of evidence suggesting that the CAS measurements of small crystals in anvil cirrus are strongly influenced by artifacts of large-crystal shattering on the instrument inlet. First, we compared the CAS small-particle measurements with those from the 2D-S instrument. The 2D-S probe is physically designed to limit shattering, and interarrival times are used to identify and remove shattering artifacts in the 2D-S dataset. The CAS small-particle concentrations are consistently 1-2 orders of magnitude higher than the 2D-S small particle concentrations. The discrepancy extends throughout the overlapping size range for the two instruments $(\simeq 10-50 \mu \mathrm{m})$.

Second, we examined the relationship between the ratio of small-crystal concentrations indicated by CAS and 2D-S and the large-crystal mass. These two quantities are strongly correlated: as large-crystal mass increases, the CAS/2D-S concentration ratio increases. This dependence is consistent with shattering contamination in the CAS dataset. There is no known reason to expect that an undercounting of smallparticles by the $2 \mathrm{D}-\mathrm{S}$ probe would result in such a correlation with large-crystal mass.

Lastly, we examined the correlation between small-crystal concentration and large-crystal mass indicated by the different instruments. As anvils age, gravitational size sorting tends to separate large and small crystals. Hence, in aged anvil cirrus, the expectation is that there will be regions with plentiful large crystals and relatively few small crystals. In the DC-8 2D-S dataset such regions are apparent, and the correlation between small-crystal concentration and largecrystal mass is relatively weak. In contrast, the CAPS dataset indicates a strong correlation between small-crystal concentration (indicated by the CAS probe) and large-crystal mass (indicated by the CIP probe), as well as an absence of regions with abundant large crystals and relatively few small crystals. The correlation indicated by the CAPS data is to be expected if the small-crystal concentration were strongly enhanced by large crystal shattering.

McFarquhar et al. (2007) reported very similar findings when comparing CAS measurements with the CDP measurements of anvil cirrus in the TWP-ICE campaign. Taken together, these results provide compelling evidence indicating that the CAS measurements of small crystals are substantially enhanced by shattering artifacts in tropical anvil cirrus. We suggest that past CAS cirrus datasets should be considered suspect when large crystals are present. In particular, the CRYSTAL-FACE CAS measurements in anvil cirrus are likely strongly enhanced artifacts, and the findings based on those measurements should be revisited. Shattering will likely have a significantly reduced effect on the CAS probe when large ice crystals are predominantly absent. However, quantifying the small-crystal artifact production from largecrystal shattering will be challenging given dependencies on a number of factors, including crystal habit, airspeed, and 
angle of attack. As an approximate measure for quantifying the impact of shattering on CAS measurements as a function of large-crystal mass present, scatter plots and linear fits are presented (Fig. 6) for spurious CAS concentration, extinction, and ice water content versus large-crystal IWC.

We also showed a significant correlation between smallcrystal concentration and large-crystal mass in the WB-57 2D-S anvil cirrus measurements. We hypothesize that this correlation was caused by shattering artifacts from large crystals impacting the leading edge of the wing and subsequently being swept back to the 2D-S probe mounted $2 \mathrm{~m}$ back under the wing. These artifacts cannot be identified and removed using interarrival times because they become spatially separated in the sheared flow under the wing. If this process is indeed occurring, then past microphysics measurement made with instruments at the wing-hatch location were presumably also affected by shattering artifacts.

Assuming the DC-8 2D-S measurements provide reliable (free from shattering artifacts) information about small $(<50 \mu \mathrm{m})$ crystals, we used this dataset to evaluate the contribution of small crystals to extinction, radiative forcing, and radiative heating in the anvil cirrus sampled during TC-4. Examining a number of cloud systems ranging from active turrets to aged anvils, we find that small crystals contribute relatively little $(<10 \%)$ to the total extinction. Using the 2D-S size distributions measured throughout the depth of an aged anvil in radiative transfer calculations, we find that the small crystals have very little impact on cloud radiative forcing or radiative heating profiles in this particular cloud.

The 2D-S small ice crystal concentrations in somewhat aged ( $\simeq 30 \mathrm{~min}$ to $3 \mathrm{~h}$ ) anvil cirrus are typically between 0.01 and $0.4 \mathrm{~cm}^{-3}$. Concentrations greater than $1 \mathrm{~cm}^{-3}$ do occur in the aged anvil cirrus, but they are rare $(<1.4 \%$ of the aged anvil cirrus measurements). The measured ice concentrations in aged anvil cirrus are substantially lower than those measured in convective turrets and fresh outflow $\left(1-30 \mathrm{~cm}^{-3}\right)$. We argue that sublimation and deposition driven by relative humidity variability in the anvils, along with other processes, likely depletes the small-crystal population rapidly. This result may be important for evaluation of what aerosols dominate the production of ice crystals that persist in aging anvil cirrus. Aerosols entrained into convective updrafts in the middle and upper troposphere that subsequently act as sites for formation of droplets and ice crystals will produce hydrometeors later than aerosols in the lowermost troposphere. As a result, the ice crystals produced by middle and upper tropospheric aerosols may produce the smallest ice crystals detrained into anvil cirrus that will be the first to sublimate as dry air is entrained.

The findings reported here do not imply that small crystals don't play a significant role in the radiative properties of other types of cirrus, such as anvils generated by continental convection, midlatitude cirrus, or even other tropical regions. Numerical simulations have suggested that homogeneous freezing of aqueous aerosols can generate large
MODIS Airborne Simulator 22 July 2007
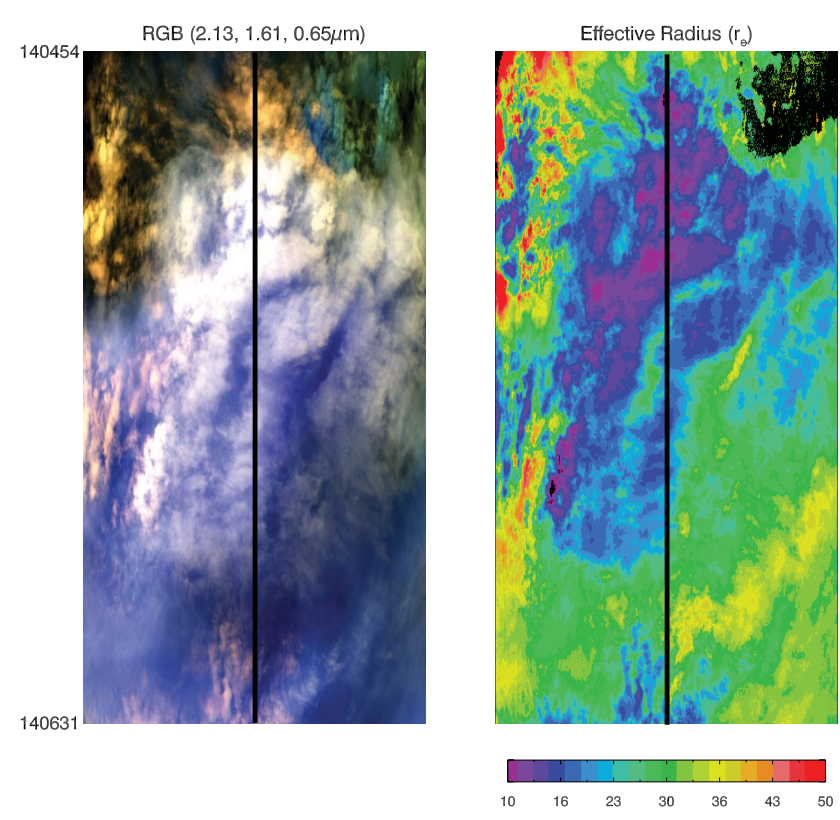

Fig. 16. Modis Airborne Simulator RGB image (left) and retrieved effective radius (right) for the time period on 22 July corresponding to Figure 15. The cloud structure suggests small-scale convection. The black line through the center of the image shows the DC-8 flight track, which was essentially directly below the ER-2.

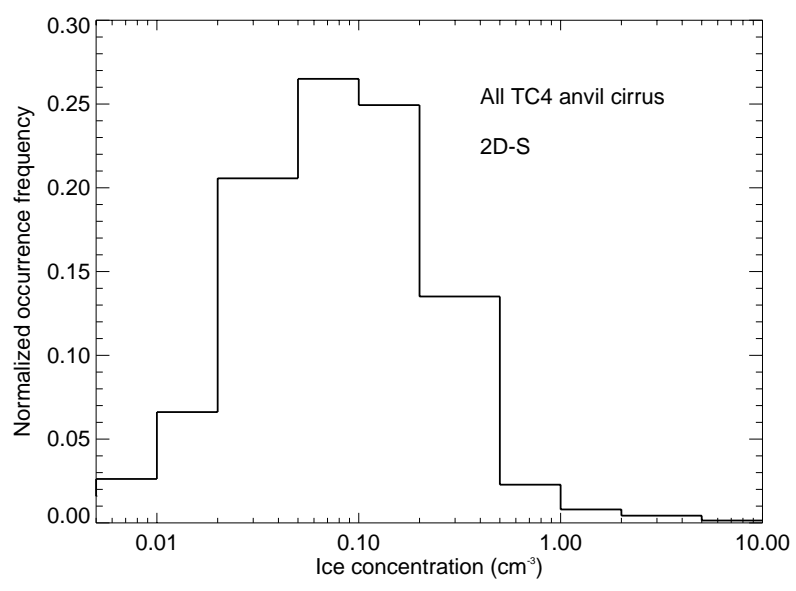

Fig. 17. 2D-S ice number concentration frequency distributions from all TC-4 DC-8 anvil sampling periods (over $13 \mathrm{~h}$ of $1-\mathrm{Hz}$ data). The convective turrets sampled on 22 and 24 July are excluded. Ice concentrations exceeding $1 \mathrm{~cm}^{-3}$ occur less than $1.4 \%$ of the time.

ice concentrations in very high, cold cumulonimbus clouds Jensen and Ackerman (2006). Also, the uppermost tropical tropopause is often saturated with respect to ice (Jensen et al., 2001), perhaps allowing small crystals to persist even as ambient air is entrained into the anvils. The TC- 4 anvil cirrus measurements discussed here were relatively low and warm, where the ambient air is typically significantly subsaturated. Knollenberg et al. (1993) used a modified 2D-C to 
get forward-scattering spectrometer measurements of small crystals near the tops of very high, cold tropical cirrus. They reported very high concentrations $\left(>10 \mathrm{~cm}^{-3}\right)$ of small crystals. Given the general lack of crystals larger than $\simeq 100 \mu \mathrm{m}$ in the cloud-top regions sampled, it is possible that these measurements were not substantially contaminated by shattering artifacts. However, it is difficult to evaluate the accuracy of these measurements since the modified 2D-C was used only during the one field experiment. Recent FSSP measurements in high, cold tropical anvil cirrus indicated ice concentrations in the $0.1-1 \mathrm{~cm}^{-3}$ range (Krämer et al., 2008).

As discussed in the introduction, accurate measurements of cirrus ice crystal size distributions are necessary for evaluation of cirrus radiative effects, development and evaluation of remote-sensing algorithms, evaluation of aerosol impacts on cirrus, and ultimately representation of cirrus in climate models. The results of this study, along with other recent analyses, suggest that much of the existing database of cirrus measurements of small crystals may be suspect because of the shattering problem, at least under some conditions. This situation motivates a need for additional airborne cirrus measurements using recently-developed probes that are designed to limit shattering artifacts, along with post-processing analysis techniques to identify and remove the shattering problem. In particular, it would be valuable to make measurements in various types of cirrus, including synoptically generated mid-latitude cirrus, anvil cirrus produced by continental convection, and anvil cirrus in the cold, uppermost tropical troposphere.

Acknowledgements. This work was supported by NASA's Radiation Science Program. The contribution by S. Tanelli was performed at the Jet Propulsion Laboratory, California Insitute of Technology under contract with the National Aeronautics and Space Administration.

\section{References}

Bacon, N. J., Swanson, B. D., Baker, M. B., and Davis, E. J.: Breakup of levitated frost particles, J. Geophys. Res., 103, 13763-13775, 1998.

Baker, B., Mo, Q., Lawson, R. P., Korolev, A., and O'Connor, D.: Drop size distributions and the lack of small drops in RICO rain shafts, J. Atmos. Sci., 1, in press, 2009.

Baker, B. R. P. L.: Improvement in determination of ice water content from two-dimensional particle imagery: Part 1: Image-toMass relationships, J. Appl. Meteorol., 45, 1282-1290, 2006.

Baumgardner, D., Jonsson, H., Dawson, W., Connor, D. O., and Newton, R.: The cloud, aerosol and precipitation spectrometer (CAPS): A new instrument for cloud investigations, Atmos. Res., 59, 59-60, 2001.

Baumgardner, D., Chepfer, H., Raga, G. B., and Kok, G. L.: The shapes of very small cirrus particles derived from in situ measurements, Geophys. Res. Lett., 32, L01806, doi:10.1029/2004GL021 300, 2005.

Chepfer, H., Noel, V., Minnis, P., Baumgardner, D., Nguyen, L., Raga, G., McGill, M. J., and Yang, P.: Particle habit in tropical ice clouds during CRYSTAL-FACE: Comparison with two remote sensing techniques and with in situ observations, J. Geophys. Res., 110, L03813, doi:10.1029/2004JD005 455, 2005.

Comstock, J. M., Lin, R.-F., Starr, D. O., and Yang, P.: Understanding ice supersaturation, particle growth, and number concentration in cirrus clouds, J. Geophys. Res., 113, D23211, doi:10.1029/2008JD010332, 2008.

Cotton, R. J. and Field, P. R.: Ice nucleation characteristics of an isolated wave cloud, Quart. J. Roy. Meteor. Soc., 128, 24172437, doi:10.1256/qj.01.150, 2002.

Cziczo, D. J., Murphy, D. M., Hudson, P. K., and Thomson, D. S.: Single particle measurements of the chemical composition of cirrus ice residue during CRYSTAL-FACE, J. Geophys. Res., 109, L12116, doi:10.1029/2003JD004 032, 2004.

Davis, S. M., Avallone, L. M., Kahn, B. H., Meyer, K. G., and Baumgardner, D.: Comparison of airborne in situ measurements and Moderate Resolution Imaging Spectroradiometer (MODIS) retrievals of cirrus cloud optical and microphysical properties during the Midlatitude Cirrus Experiment (MidCiX), J. Geophys. Res., 114, D02203, doi:10.1029/2008JD010 284, 2009.

Field, P. R., Wood, R., Brown, P. R. A., Kaye, P. H., Hirst, E., and Greeaway, R.: Ice particle interarrival times measured with a fast FSSP, J. Atmos. Ocean. Tech., 20, 249-261, 2003.

Field, P. R., Heymsfield, A. J., and Bansemer, A.: A test of ice selfcollection kernels using aircraft data, J. Atmos. Sci., 63, 651666, 2006.

Fridlind, A. M., Ackerman, A. S., Jensen, E. J., Heymsfield, A. J., Poellot, M. R., Stevens, D. E., Wang, D., Miloshevich, L. M., Baumgardner, D., Lawson, R. P., Wilson, J. C., Flagan, R. C., Seinfeld, J. H., Jonsson, H. H., VanReken, T. M., Varutbangkul, V., and Rissman, T. A.: Evidence for the predominance of midtropospheric aerosols as subtropical anvil nuclei, Science, 303, 718-722, 2004.

Fridlind, A. M., Ackerman, A. S., McFarquhar, G., Zhang, G., Poellot, M. R., DeMott, P. J., Prenni, A. J., and Heymsfield, A. J.: Ice properties of single-layer stratocumulus during the Mixed-Phase Arctic Cloud Experiment: 2. Model results, J. Geophys. Res., 112, D24202, doi:10.1029/2007JD008 646, 2007.

Gardiner, B. A. and Hallett, J.: Degradation of in-cloud Forward Scattering Spectrometer Probe measurements in the presence of ice crystals, J. Atmos. Ocean. Tech., 2, 171-180, 1985.

Garrett, T. J., Navarro, B. C., Twohy, C. H., Jensen, E. J., Baumgardner, D. G., Bui, P. T., Gerber, H., Herman, R. L., heymsfield, A. J., Lawson, P., Minnis, P., Nguyen, L., Poellot, M., Pope, S. K., Valero, F. P. J., and Weinstock, E. M.: Evolution of a Florida Cirrus Anvil, J. Atmos. Sci., 62, 2352-2372, 2005.

Gayet, J.-F., Febvre, G., and Larsen, H.: The reliability of the PMS FSSP in the presence of small ice crystals, J. Atmos. Ocean. Tech., 13, 1300-1310, 1996.

Gayet, J.-F., Auriol, F., Minikin, A., Ström, J., Seifert, M., Krejci, R., Petzold, A., Febvre, G., and Schumann, U.: Quantitative measurement of the microphysical and optical properties of cirrus clouds with four different insitu probes: Evidence of small ice crystals, Geophys. Res. Lett., 29, 2230, doi:10.1029/2001GL014342, 2002.

Heymsfield, A. J.: On measurements of small ice particles in clouds, Geophys. Res. Lett., 34, doi:10.1029/2007GL030 951, 2007.

Heymsfield, A. J. and McFarquhar, G. M.: On the high albedos of anvil cirrus in the tropical Pacific warm pool: Microphysical 
interpretations from CEPEX and Kwajalein, Marshall Islands, J. Atmos. Sci., 53, 2424-2451, 1996.

Heymsfield, A. J. and Miloshevich, L. M.: Relative humidity and temperature influences on cirrus formation and evolution: Observations from wave clouds and FIRE II, J. Atmos. Sci., 52, 4302-4326, 1995.

Hong, G., Yang, P., Gao, B.-C., Baum, B. A., Hu, Y. X., King, M. D., and Platnick, S.: High cloud properties from three years of MODIS Terra and Aqua collection-4 data over the tropics, J. Appl. Meteorol. Clim., 46, 1840-1856, 2007.

Hoyle, C. R., Luo, B. P., and Peter, T.: The origin of high ice crystal number densities in cirrus clouds, J. Atmos. Sci., 62, 2568-2579, 2005.

Ivanova, D., Mitchell, D. L., Arnott, W. P., and Poellot, M.: A GCM parameterization for bimodal size spectra and ice mass removal rates in mid-latitude cirrus clouds, Atmos. Res., 59, 89113, 2001.

Jensen, E. J. and Ackerman, A. S.: Homogeneous aerosol freezing in the tops of high-altitude tropical cumulonimbus clouds, Geophys. Res. Lett., 33, L08802, doi:10.1029/2005GL024 928, 2006.

Jensen, E. J., Kinne, S., and Toon, O. B.: Tropical cirrus cloud radiative forcing: Sensitivity studies, Geophys. Res. Lett., 21, 2023-2026, 1994.

Jensen, E. J., Toon, O. B., Tabazadeh, A., Sachse, G. W., Anderson, B. E., Chan, K. R., Baumgardner, D., Twohy, C., Gandrud, B., Heymsfield, A., Aulenbach, S., Hallett, J., and Gary, B. L.: Ice nucleation processes in upper tropospheric wave-clouds observed during SUCCESS, Geophys. Res. Lett., 25, 1363-1366, 1998.

Jensen, E. J., Pfister, L., Ackerman, A. S., and Tabazadeh, A.: A conceptual model of the dehydration of air due to freeze-drying by optically thin, laminar cirrus rising slowly across the tropical tropopause, J. Geophys. Res., 106, 17273-17252, 2001.

Kärcher, B. and Ström, J.: The roles of dynamical variability and aerosols in cirrus cloud formation, Atmos. Chem. Phys., 3, 823838,2003 ,

http://www.atmos-chem-phys.net/3/823/2003/.

Knollenberg, R. G., Kelly, K., and Wilson, J. C.: Measurements of high number densities of ice crystals in the tops of tropical cumulonimbus, J. Geophys. Res., 98, 8639-8664, 1993.

Korolev, A.: Reconstruction of the sizes of spherical particles from their shadow images. Part I: Theoretical considerations, J. Atmos. Ocean. Tech., 24, 376-389, 2007.

Korolev, A. and Isaac, G. A.: Shattering during sampling by OAPs and HVPS. Part I: Snow particles, J. Atmos. Ocean. Tech., 22, 528-542, 2005.

Krämer, M., Schiller, C., Afchine, A., Bauer, R., Gensch, I., Mangold, A., Schlicht, S., Spelten, N., Sitnikov, N., Borrmann, S., de Reus, M., and Spichtinger, P.: Ice supersaturations and cirrus cloud crystal numbers, Atmos. Chem. Phys. Discuss., 8, 2108921128, 2008, http://www.atmos-chem-phys-discuss.net/8/21089/2008/.

Lawson, R. P., Baker, B. A., Pilson, B., and Mo, Q.: In Situ observations of the microphysical properties of wave, cirrus and anvil clouds. Part II: Cirrus clouds, J. Atmos. Sci., 63, 3186-3203, 2006a.

Lawson, R. P., O'Connor, D., Zmarzly, P., Weaver, K., Baker, B. A., Mo, Q., and Jonsson, H.: The 2D-S (Stereo) probe: Design and preliminary tests of a new airborne, high-speed, high-resolution imaging probe, J. Atmos. Ocean. Tech., 23, 1462-1477, $2006 \mathrm{~b}$.

Lawson, R. P., Pilson, B., Baker, B., Mo, Q., Jensen, E., Pfister, L., and Bui, P.: Aircraft measurements of microphysical properties of subvisible cirrus in the tropical tropopause layer, Atmos. Chem. Phys., 8, 1609-1620, 2008,

http://www.atmos-chem-phys.net/8/1609/2008/.

Magee, N., Moyle, A. M., and Lamb, D.: Experimental determination of the deposition coefficient of small cirrus-like ice crystals near $-50^{\circ} \mathrm{C}$, Geophys. Res. Lett., 33, L17813, doi:10.1029/2006GL026 665, 2006.

McFarquhar, G. M. and Heymsfield, A. J.: Parameterization of tropical cirrus ice crystal size distributions and implications for radiative transfer: results from CEPEX, J. Atmos. Sci., 54, 21872200, 1997.

McFarquhar, G. M., Um, J., Freer, M., Baumgardner, D., Kok, G. L., and Mace, G.: The importance of small ice crystals to cirrus properties: Observations from the Tropical Warm Pool International cloud Experiment (TWP-ICE), Geophys. Res. Lett., 57, L13803, doi:10.1029/2007GL029 865, 2007.

Miloshevich, L. M. and Heymsfield, A. J.: A balloon-borne continuous cloud particle replicator for measuring vertical profiles of cloud microphysical properties: Instrument design, performance, and collection efficiency analysis, J. Atmos. Ocean. Tech., 14, 753-768, 1997.

Mitchell, D. L., Rasch, P., Ivanova, D., McFarquhar, G., and Nousianen, T.: The impact of small ice crystal assumptions on sedimentation rates and GCM simulations, Geophys. Res.Lett., 35, L09806, doi:10.1029/2008GL033 552, 2008.

Platt, C. M. R., Spinhirne, J. D., and Hart, W. D.: Optical and microphysical properties of a cold cirrus cloud: Evidence for regions of small ice particles, J. Geophys. Res., 41, 11151-11164, 1989.

Sadowy, G. A., Berkun, A. C., Chun, W., Im, E., and Durden, S. L.: Development of an advanced airborne precipitation radar, $\mathrm{Mi}$ crowave J., 46, 84-98, 2003.

Sanderson, B. M., Piani, C., Ingram, W. J., Stone, D. A., and Allen, M. R.: Towards constraining climate sensitivity by linear analysis of feedback patterns in thousands of perturbed-physics GCM simulations, Clim. Dyn., 30, 2-3, doi:10.1007/s00 382007-0280-7, 2008.

Stackhouse, P. W. J. and Stephens, G. L.: A theoretical and observational study of the radiative properties of cirrus: Results from FIRE 1986, J. Atmos. Sci., 48, 2044-2059, 1991.

Ström, J., Strauss, B., Anderson, T., Schröder, F., Heintzenberg, J., and Wendling, P.: In situ observations of the microphysical properties of young cirrus clouds, J. Atmos. Sci., 54, 2542-2553, 1997.

Toon, O. B., McKay, C. P., Ackerman, T. P., and Santhaman, K.: Rapid calculation of radiative heating and photodissociation rates in inhomogeneous multiple scattering atmospheres, J. Geophys. Res., 94, 16287-16301, 1989.

Twohy, C. H. and Poellot, M. R.: Chemical characteristics of ice residual nuclei in anvil cirrus clouds: evidence for homogeneous and heterogeneous ice formation, Atmos. Chem. Phys., 5, 22892297, 2005, http://www.atmos-chem-phys.net/5/2289/2005/.

Zender, C. S. and Kiehl, J. T.: Radiative sensitivities of tropical anvils to small ice crystals, J. Geophys. Res., 99, 25,869-25,880, 1994. 